\title{
Ambient sesquiterpene concentration and its link to air ion measurements
}

\author{
B. Bonn ${ }^{1, *}$, A. Hirsikko ${ }^{1}$, H. Hakola ${ }^{2}$, T. Kurtén ${ }^{1}$, L. Laakso ${ }^{1}$, M. Boy ${ }^{3}$, M. Dal Maso ${ }^{1}$, J. M. Mäkelä ${ }^{4}$, and \\ M. Kulmala ${ }^{1}$ \\ ${ }^{1}$ Department of Physical Sciences, University of Helsinki, Helsinki, Finland \\ ${ }^{2}$ Finnish Meteorological Institute, Helsinki, Finland \\ ${ }^{3}$ National Center of Atmospheric Research, Boulder, CO, USA \\ ${ }^{4}$ Tampere University of Technology, Institute of Physics, Tampere, Finland \\ * now at: Estonian University of Life Sciences, Department of Plant Physiology, Tartu, Estonia
}

Received: 4 October 2006 - Published in Atmos. Chem. Phys. Discuss.: 15 December 2006

Revised: 16 April 2007 - Accepted: 25 May 2007 - Published: 11 June 2007

\begin{abstract}
Ambient air ion size distributions have been measured continuously at the Finnish boreal forest site in Hyytiälä since spring 2003. In general, these measurements show a maximum of air ions below $1.0 \mathrm{~nm}$ in diameter. But this physical characterization does not provide any information about the ion's chemical composition, which is one key question regarding the explanation of nucleation events observed. In this study we propose a link of the observed maximum of negative air ions between 0.56 and $0.75 \mathrm{~nm}$ to the socalled stabilised Criegee biradical, formed in the reaction of biogenic sesquiterpenes with ozone and predominantly destroyed by its reaction with ambient water vapour. Calculations of the electron and proton affinities of $120 \mathrm{~kJ} \mathrm{~mol}^{-1}$ $(1.24 \mathrm{eV})$ and of $960 \mathrm{~kJ} \mathrm{~mol}^{-1}$ support this link. Other possible candidates such as sulphuric acid derived clusters are unable to explain the observations made. By using this approach, we are able to calculate the ambient concentration of sesquiterpenes at the air ion instrument inlet with a high time resolution on the daily and seasonal scale. The estimated concentration is found to reveal the same seasonal pattern as emission measurements conducted at shoot level. As expected for biogenic VOCs, the concentration is obtained highest during summer (maximum values of about $100 \mathrm{pptv}$ ) and smallest during winter (minimum less than $1 \mathrm{pptv}$ ). Because of the sesquiterpenes high reactivity and its low ambient concentrations, this approach can be a first step in understanding their emission and their impact on atmospheric chemistry in more detail. The findings presented are highly relevant for emission budgets too, since boreal forests are extended over large areas of the globe.
\end{abstract}

Correspondence to: B. Bonn

(boris.bonn@helsinki.fi)

\section{Introduction}

Boreal forests cover approximately $16 \%$ of the Earths' land surface. They include a mixture of different tree types such as pine and spruce as well as smaller surface vegetation types on different soils. This vegetation emits various types of volatile organic compounds (VOCs) because of stress factors such as temperature, draught and hazardous oxidants (e.g. ozone), which affect the vegetation. Recent measurements in boreal environments (Goldstein et al., 2004; Hakola et al., 2003, 2006; Hellén et al., 2004; Tarvainen et al., 2005; Vuorinen et al., 2005) with respect to the involved trees have shown that these compounds mainly consist of monoterpenes $\left(\mathrm{C}_{10} \mathrm{H}_{16}\right)$ and carbonyl compounds. Once the VOCs are emitted, they start to react with ambient oxidants (ozone, $\mathrm{OH}$ and $\mathrm{NO}_{3}$ ), resulting in atmospheric lifetimes, their survival time in the atmosphere respectively, of several hours to days. However, sesquiterpenes $\left(\mathrm{C}_{15} \mathrm{H}_{24}\right)$, a class of compounds, which are highly reactive especially towards ozone, have been detected in notable amounts in emission studies (Hakola et al., 2006), when ozone was removed from the sampling air before entering the glass cuvette enclosing the emitting tree branch. But their detection in ambient air is limited by their short atmospheric lifetime of about 1-2 min, almost exclusively caused by the reaction with ambient ozone and the resulting lower ambient concentration. Currently, ambient sesquiterpene concentration measurements are only possible if their concentration exceeds about 20 parts per trillion (pptv), which might be only achieved close to the emitting needles but nowhere else in boreal forests, except during summer time.

In these forests new particle formation is known to occur, first reported by F. W. Went in his article on blue haze (Went, 1960). He linked the appearance of blue haze or visible new particle formation to biogenic monoterpenes

Published by Copernicus GmbH on behalf of the European Geosciences Union. 
$\left(\mathrm{C}_{10} \mathrm{H}_{15}\right)$ emitted by the forest subsequently reacting with ozone. Similar particle formation events have been observed rather frequently at the Finnish boreal forest site in Hyytiälä $\left(61^{\circ} 51^{\prime} \mathrm{N}, 24^{\circ} 17^{\prime} \mathrm{E}, 180 \mathrm{~m}\right.$ a.s.l.) with about $60-120$ events per year (Dal Maso et al., 2005). However, compared to monoterpenes the larger sesquiterpenes and their oxidation products are believed to play an even stronger role in nucleation, but have not been able to study at Hyytiälä yet. The knowledge of their emission and concentration on a high time resolution as well as of the oxidation products involved are some of the missing key information.

In order to understand the biosphere-atmosphere exchange, various parameters are measured continuously since 1996 at the Station for Measuring forest EcosystemAtmosphere Relations (SMEAR) II in Hyytiälä. These focus on the biogenic interaction (fluxes, growth, respiration) with the atmospheric conditions (meteorological parameters and trace gases) and on the onset of new particle formation particle number concentrations and size distributions). From spring 2003 on the size distributions of air ions are measured with two different devices too. In these measurements a clear maximum of ambient negative air ions at sizes between 0.56$0.75 \mathrm{~nm}$ (electrical mobility range at standard conditions, i.e. $T=273.15 \mathrm{~K}$ and $p=101325 \mathrm{~Pa}$ ): $1.96-1.48 \mathrm{~cm}^{2} \mathrm{~V}^{-1} \mathrm{~s}^{-1}$ ) and of positive charged ones between 0.75 and $1.0 \mathrm{~nm}$ (electrical mobility range: $1.48-1.04 \mathrm{~cm}^{2} \mathrm{~V}^{-1} \mathrm{~s}^{-1}$ ) in mobility derived diameter are apparent. In order to improve our understanding of the biosphere-atmosphere interactions, the origin of nucleation and the whole nucleation process, the chemical nature of these air ions is essential to know in order to draw further conclusions about their detailed role or function in the processes involved.

\section{Atmospheric air ions}

Atmospheric air ions describe molecules, clusters or particles carrying one or more electric charges. The charge originates either from radioactive decay of Radon and the release of $\gamma$ radiation from soil sources or from cosmic rays. Next, the tiny formed electrons and positively charged ions will attach rapidly to the next molecule, cluster or particle reached first with the capability to accept the offered charge, i.e. with sufficiently large electron or proton affinities.

At the sampling site in Finland, air ions larger than $0.4 \mathrm{~nm}$ in "Tammet" diameter (Tammet, 1995, 2005) are measured continuously. In this context "mobility" refers to the measurement technique: The dynamic movement within an electrical field $\vec{E}$ of a capacitor in the instrument is detected. Because of the lack of knowledge about the real structure, a spherical shape is applied for the air ions. Their movement in the electrical field applied is commonly expressed as electrical mobility $Z_{e l}$. This electrical mobility describes the speed $v_{e l}$, caused by the interaction of the total ion charge $i \cdot e$ with the applied external electrical field, which is balanced by the drag. The drag is represented by the friction coefficient $f$ of an idealized spherical object with a so-called mobility diameter (Friedlander, 2000):

$Z_{e l}=\frac{v_{e l}}{E}=\frac{i e}{f}$

For analysis the ions are introduced into the electrical field within a large sample flow to minimize any wall losses and are detected by capacitor pulses for both polarities. Because of the electro neutrality of ambient air both polarities are expected in similar quantities, i.e. the number of negative air ions $N_{\text {ions,- }}$ equals the one of positive air ions $N_{\text {ions, }+}$ :

$N_{\text {ions, }-}=N_{\text {ions, }+}$

These ions are distributed over a huge size range between less than a nanometer and several microns. The individual fraction of the present neutral molecules, clusters or particles (named neutrals in the following) that becomes charged under atmospheric equilibrium conditions differs remarkably, depending on the physical and chemical properties of the neutrals. These properties are the size, the atmospheric lifetime and the affinities (electron and proton affinity) of the neutrals to accept positive or negative charges. The charging process itself occurs via collisions of neutrals with ambient air ions, i.e. already charged particles or newly formed electrons and positive complements. For the size range of interest, which is less than a few nanometers, the steady-state collision frequency $\beta_{i} \cdot A$ is given as (Seinfeld and Pandis, 1998):

$$
\begin{aligned}
\beta_{i} & =2 \pi\left(d_{p, i}+d_{\text {ion }}\right)\left(D_{1}+D_{\text {ion }}\right) \beta_{M} \\
\beta_{M} & =\frac{K n+1}{0.377 K n+1+\frac{3}{4 \alpha} K n^{2}+\frac{3}{4 \alpha} K n} \\
K n & =\frac{2 \lambda_{\text {air }}}{d_{\text {ion }}} \\
A & =1+2 \sqrt{\frac{1}{4 \pi \epsilon_{0}} \frac{\pi q^{2}}{4 D_{p} k T}}
\end{aligned}
$$

In here the collision rate of neutral and ion is been splitted into a "neutral" (collision frequency of a neutral $\beta$ ) and an ion-part (enhancement factor $A$ ), which can be found for instance in Eq. (3) of Tammet (2005). The index $i$ represents the size section of interest. Furthermore, $d_{p, i}$ and $d_{\text {ion }}$ denote the diameters of the neutral (in size section i) and the air ion, and $D_{1}$ and $D_{\text {ion }}$ the corresponding diffusion coefficients. $\beta_{M}$ is the transitional correction factor for the transition between the free molecular regime $\left(d_{p, i} \ll\right.$ mean free path $\left.\lambda_{\text {air }}\right)$ and the continuum regime $\left(d_{p, i} \gg\right.$ mean free path $\left.\lambda_{\text {air }}\right)$ given by Fuchs and Sutugin (1971). For its calculation, the Knudsen number $\mathrm{Kn}$ and the sticking probability $\alpha$ are used. The remaining factor $A$ is the so-called enhancement factor, due to the impact of the Coulomb forces of the air ions (Hoppel and Frick, 1986; Laakso et al., 2002). The enhancement factor considers the affinity of a neutral to polarize in the presence of an external charge causing the neutral to attract or 
repulse the ion of opposite charge. Hence, negative ions will be attracted by the positively charged part and repelled by the negatively charged one. $q$ stands for the elementary charge of $1.6 \times 10^{-19} C$ and $\epsilon_{0}$ is the vacuum permittivity. For further details see for example Friedlander (2000), Seinfeld and Pandis (1998) or Laakso et al. (2002).

It is well known that the collision frequency is highest for molecules, clusters or particles with remarkably different sizes on the contrary to the ones of similar sizes. The collision rates are spanning several orders of magnitude for the collision of a single molecule with an object of a diameter between $1 \mathrm{~nm}$ and $1 \mu \mathrm{m}$. This causes newly formed air ions, i.e. electrons and singly charged molecules, to collide most efficiently with larger aerosol particles, depending on the aerosols surface chemical properties (charge affinities), already adsorbed charges and concentrations.

\section{Focus of this study and hypothesis}

In study we aim to understand the chemical composition of air ions measured at the Finnish boreal forest field station in Hyytiälä (Sect. 4) in the smallest size range $\left(D_{p}<1 \mathrm{~nm}\right.$ in diameter) with a specific focus on the size range between 0.56 and $0.75 \mathrm{~nm}$ in diameter, in which the maximum of negative air ions is located. In order to do so, we start by deducing the charged fraction of compounds, clusters or particles at the very smallest sizes and investigate the parameters affecting this (Sect. 5.2). Next, we are focussing on the possible mass ranges and related compounds in the size section between 0.56 and $0.75 \mathrm{~nm}$ in diameter (Sect. 5.3) and calculate the electron and proton affinities for the most promising compounds (Sect. 5.4). By intercomparison with observations as for instance concentration and the ratio of negative and positive air ions, we formulate requirements the possible candidates have to fulfil in order to explain the observations. This leads to our hypothesis, presented in this paper, that ambient air ions measured in the size range between 0.56 and $0.75 \mathrm{~nm}$ mainly consist of a specific biradical, i.e. the stabilised Criegee intermediate, which is formed by the highly reactive biogenic sesquiterpenes with ozone.

In this case we can use the air ion concentration measured for an approximation of ambient sesquiterpene concentrations (Sect. 6) even below a concentration of $1 \mathrm{pptv}$, a range not able to be studied before. Finally, we examine the effect of the 'maximum' assumption that all air ions in this section consist of stabilised Criegee intermediates on the derived sesquiterpene concentration and discuss the assumption of treating single molecules instead of molecular clusters.

\section{Experimental}

Ambient air ion mobility (size) distributions have been measured continuously since spring 2003 at the SMEAR II of the Helsinki University in Hyytiälä. It is located about
$50 \mathrm{~km}$ northeast of Tampere and about $100 \mathrm{~km}$ southwest of Jyväskylä and represents boreal forest background conditions inside a 44-year-old homogeneous pine forest, which is extending several kilometers to the north and northeast. About $1 \mathrm{~km}$ to the southwest is a small lake with the station buildings closed by (Kulmala et al., 2001).

For air ion measurements two instruments have been used: (i) the Balanced Scanning Mobility Analyzer (BSMA) (Sect. 4.1) and (ii) the Air Ion Spectrometer (AIS) (Sect. 4.2). Both instruments measured the ion mobility distribution for positive and for negative ions simultaneously. In this study we focus predominantly on the measurements of the BSMA because of the higher flow rates and smaller losses inside the instrument. The datasets obtained with the AIS are used for intercomparison only.

\subsection{BSMA}

The BSMA instrument from Airel Ltd. (Estonia) consists of two plain parallel aspiration-type condensers. The voltage and thus the electrical field applied inside the condensers are changed continuously. To measure the air ion size distribution $22 \mathrm{~L} \mathrm{~s}^{-1}$ are introduced into each condenser to minimize sampling losses. With this set-up the mobility distribution of air ions was measured in 16 logarithmically equidistant sections between $0.032-3.16 \mathrm{~cm}^{2} \mathrm{~V}^{-1} \mathrm{~s}^{-1}$ within three minutes. The obtained mobility distribution was averaged over $15 \mathrm{~min}$ and converted afterwards to the size range of $0.42-7.5 \mathrm{~nm}$ by applying the algorithm given by Tammet $(1995,1998)$. This algorithm takes the influence of temperature and pressure into account and calculates the size distribution in 10 logarithmically equidistant sections. The operational principle of the BSMA is described in more detail elsewhere (Tammet, 2004; Hirsikko et al., 2005). In the middle of August 2005 the measuring cycle of the BSMA were changed according to Tammet (2006) and because of that we concentrated the present study on the time before that in order to exclude artifacts caused by the change.

\subsection{AIS}

The Air Ion Spectrometer (AIS) is manufactured as well by Airel Ltd. By contrast to the BSMA it consists of two cylindrical differential mobility analysers (DMA) with 21 collector electrodes each. Each DMA was used for a single polarity. The sample flow rate for each DMA was $0.5 \mathrm{~L} \mathrm{~s}^{-1}$ $\left(1 \mathrm{~L} \mathrm{~s}^{-1}\right.$ in total $)$ and the sheath flow inside the DMA was twice as large. With this set-up the entire mobility range between $0.0013-2.4 \mathrm{~cm}^{2} \mathrm{~V}^{-1} \mathrm{~s}^{-1}$ was measured within $5 \mathrm{~min}$. Similar to the BSMA the background signal was recorded and subtracted from the measurement signal for ambient air. Afterwards the algorithm of Tammet (1995) was applied here too in order to obtain the corresponding size range.

Because of the much smaller sample flow rate of AIS compared to the BSMA, larger air ion losses need to be taken into 
account during the calculation of the size distribution and of the actual air ion concentration from AIS datasets. Therefore, we focussed our analysis mainly on the datasets gained by BSMA measurements, but used the results obtained by AIS measurements for intercomparison in order to check for artifacts.

In this context it should be noted that all results shown in the following are apparent for both instruments, indicating that there are none of these kind of artifacts and the results of both instruments support the results presented.

For further analysis we increased the averaging time scale to $30 \mathrm{~min}$ to make the ion measurements intercomparable with available trace gas and meteorological observations made at the station.

\subsection{Trace gas and meteorological parameter measurements}

Continuous observations of trace gases and meteorological parameters have been measured simultaneously at a tower of $72 \mathrm{~m}$ in height at six heights, distributed logarithmically with altitude: $4.2 \mathrm{~m}, 8.4 \mathrm{~m}, 16.8 \mathrm{~m}, 33.6 \mathrm{~m}, 50.4 \mathrm{~m}, 67.2 \mathrm{~m}$. These include e.g. solar radiation, temperature, pressure, sulphur dioxide, ozone and water vapour concentration. More details on the measurements methods of the individual trace gases can be found in Hari and Kulmala (2005) and references therein.

Emission measurements of selected organic compounds have been conducted at the shoot level inside the canopy. By purging purified air through the sampling cuvette enclosing a branch the VOCs were trapped on cartridges for usually $2 \mathrm{~h}$ to gain sufficient material. The analysis itself was carried out in the laboratory several days later. For more details on this see Hakola et al. (2006).

For this study we used trace gas from the tower at $4.2 \mathrm{~m}$ in height, which corresponds best to the height of the inlet of the air ion measurements. Sesquiterpene emission measurements were only available at shoot level and thus taken therefrom (ca. $12 \mathrm{~m}$ in altitude; Hakola et al., 2006).

\section{Results}

Since spring 2003 ambient air ion size distributions have been obtained, always displaying a maximum at small sizes, i.e. at about $0.7 \mathrm{~nm}$ in diameter for negative air ions and at about $0.95 \mathrm{~nm}$ for positive ions. This is exemplarily shown in Fig. 1 for negative air ions at the top and for the positive ones in the lower plot on three consecutive days. Since this measurement technique is physical only, no information on the chemical compounds of these air ions is directly available. However, when aiming to understand the onset of nucleation and the compounds involved in, the chemical nature of the air ions in this size range is a key information needed. Based of thermodynamical considerations Kulmala et al. (2000) suggested that the air ions between 1 and $3 \mathrm{~nm}$ in diameter might consist of thermodynamically stable sulphuric acid-water-ammonia clusters. Since the size range investigated is close by, this might apply here as well.

\subsection{Air ion measurements on the annual scale}

If we take a look on the seasonal behaviour of negative and positive air ions in the second size section measured by BSMA (spherical diameter between 0.56 and $0.75 \mathrm{~nm}$ ), a clear seasonal pattern is apparent. For both polarities the concentration is found maximum during winter $\left(\approx 300 \mathrm{~cm}^{-3}\right.$ on average) (Fig. 2). The minimum occurs during summer $\left(\approx 200 \mathrm{~cm}^{-3}\right)$, which is more pronounced for positive ions than for negative ones. In order to explain this behaviour the sources and sinks need to be considered. Let's simply assume the air ion to have a density between $1000 \mathrm{~kg} \mathrm{~m}^{-3}$ (water, CRC handbook, 1998) and $1830.5 \mathrm{~kg} \mathrm{~m}^{-3}$ (sulphuric acid, CRC handbook, 1998). Thus, the air ion must consist of a total mass between $1.31 \times 10^{-25}$ and $4.78 \times 10^{-25} \mathrm{~kg}$. This corresponds to a molar mass between 79 and $288 \mathrm{~g} \mathrm{~mol}^{-1}$. Consequently, the air ion consists most likely of a single molecule only. Chemical compounds referring to this range are multiple: sulphuric acid, various organics from anthropogenic and biogenic sources. In Sect. 5.3 of this article we will treat the required molar mass in more detail, using the mobility relationship with the molar mass given by Kilpatrick (1971). The latter more detailed approach yields larger molar masses, approximately twice as large as given in here, and thus excluding single sulphuric acid molecules. Consequently, additional information such as the annual behaviour of the air ion concentration and the charged fraction in the section of interest is required for information about the chemical composition, when assuming the major source to be similar throughout the year. This information can then be intercompared to the annual concentration variation of any possible air ion precursors.

\subsection{Derivation of charged fraction}

A crucial piece of information, when investigating charged molecules, clusters or particles and neutral ones, is the charged fraction. This one is for example used in particle size distribution measurements to conclude from the detected charged particles to the total, neutral and charged respectively, particle size distribution. In our case we investigated the size range from 0.56 to $0.75 \mathrm{~nm}$ in mobility derived diameter (Tammet, 1995), which is in the free molecular regime with both neutrals and ions either being or behaving like single molecules. Starting with the budgeting equation for the air ion concentration $N_{ \pm, i}$ in that size range, we obtain:

$$
\begin{aligned}
\frac{d N_{ \pm, i}}{d t}= & \sum_{j} \beta_{j} A N_{\text {ions }, j} N_{0} \\
& -\sum_{j} \beta_{j} A N_{\text {ions }, j} N_{ \pm, i}
\end{aligned}
$$



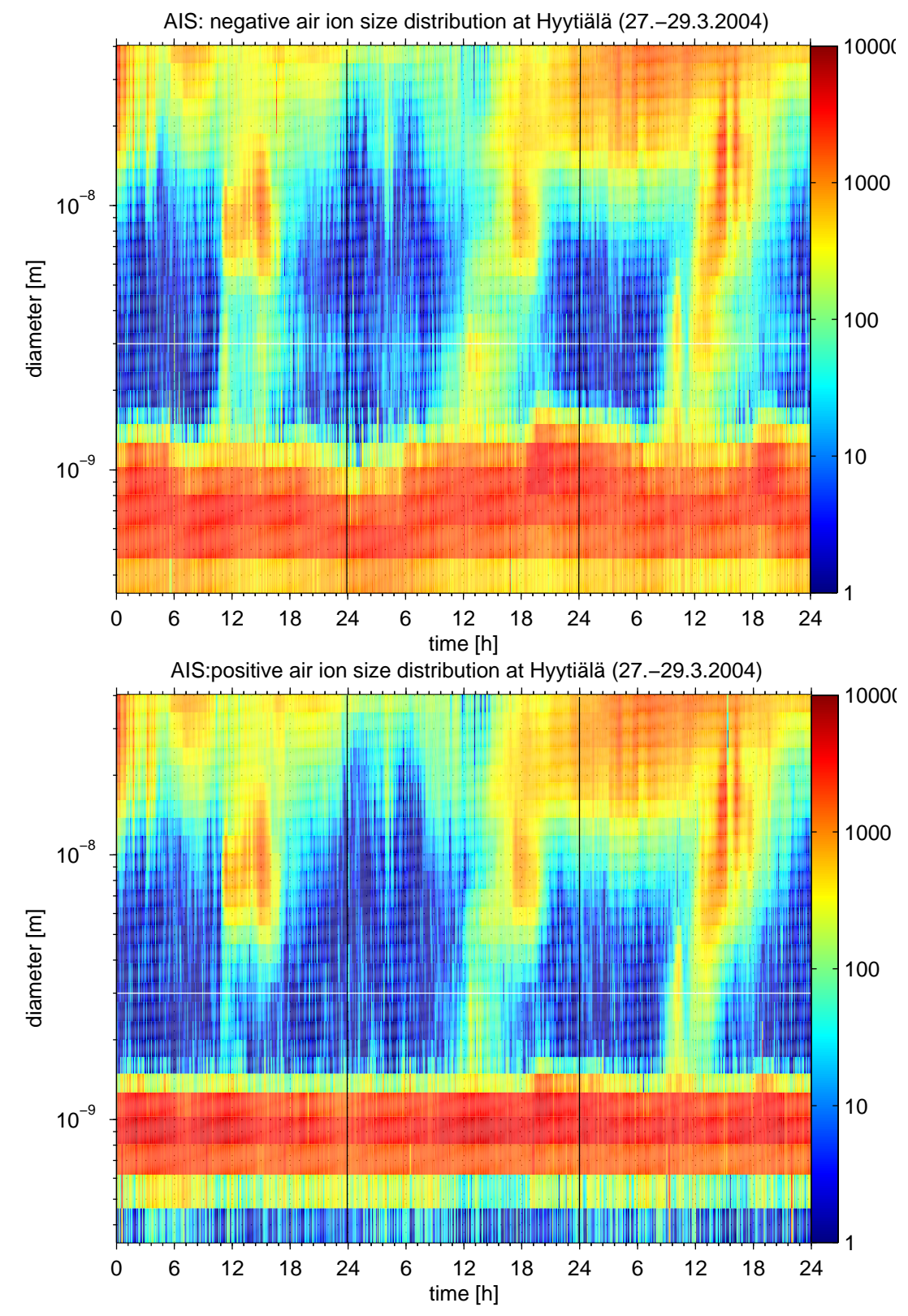

Fig. 1. Displayed are AIS size distribution measurements between 27 and 29 March 2004. In the upper panel the size distribution of negative air ions and in the lower one the size distribution of the positive ions is shown. A clear maximum is visible in the third size section in the upper plot). Because of different section limits this corresponds to the second size section of BSMA.

$$
-K_{\text {chem }} N_{ \pm, i}-C S \cdot N_{ \pm, i}-K_{\text {forest }} N_{ \pm, i}
$$

In here, the first term on the right is the production by collisions of the neutrals, matching the size range of interest $\left(N_{0}\right)$ with present ambient air ions $\left(N_{\text {ions }}\right)$, including charged aerosol particles as well. The indices $i$ and $j$, used in Eq. (7), refer to the size section: $i$ represents the budgeting size section of the air ions and $j$ is used for summation over all sizes measured. A separate growth term of even smaller ions is excluded here, since for most compounds this size range cor- responds to one or two molecules and an increase in size can be described by the collision of an air ion with a neutral molecule. Additionally, any larger air ion, sticking to the previously neutral, will cause the resulting air ion to be larger than the size section upper limit and thus does not contribute to the air ion concentration of the section investigated. Furthermore, it is assumed that the radioactive decay or $\gamma$ radiation causes electrons to be separated and subsequently attached to either a neutral or and ion of opposite charge. 


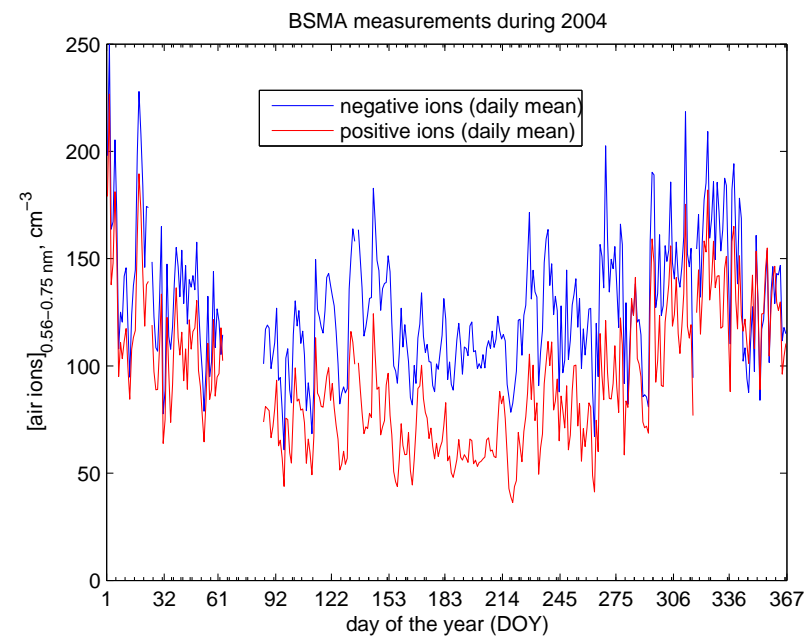

Fig. 2. Air ion concentrations between 0.56 and $0.75 \mathrm{~nm}$ for both polarities measured with the BSMA during 2004.

They cannot be detected directly due to their small size. The same applies for the positive fragment. Thus, any new ion in the investigated size section $(0.56 \mathrm{~nm} \leq$ diameter $\leq 0.75 \mathrm{~nm})$ is formed by a collision of a neutral with an ambient air ion and a subsequent charge transfer. $\beta_{i} \times A$ abbreviates the collision frequency of neutral and ion, now including the enhancement term $A$, which takes into account the electrical forces. The second term refers to the loss by recombination of two ions of different polarities. The third term is the sink by any chemical reactions. For a single loss reaction of $N_{ \pm, i}+X$ with the rate constant $k$ this results in $K_{\text {chem }}=k \cdot[X]$. Note that for more than one compound this represents the average sink for $N_{ \pm, i}$. The next term is the loss on a pre-existing aerosol surface described by the condensation sink (CS) (Pirjola et al., 1999) leading to a removal out of the mobility or size section. This is actually the reciprocal time (lifetime $\tau$ ) of the neutral before being captured. The final sink term on the right describes the forest sink as given by Tammet et al. (2006). For the measurement height of $2 \mathrm{~m}$ Tammet et al. give a value of $1.5 \times 10^{-3} \mathrm{~s}^{-1}$ for $K_{\text {forest }}$, which is close to the $C S$ values found at the site. Thus, the total lifetime of an air ion is given as:

$$
\begin{aligned}
\tau= & \frac{N_{ \pm, i}}{\operatorname{sink}} \\
= & \frac{N_{ \pm, i}}{K_{\text {chem }} N_{ \pm, i}+C S \cdot N_{ \pm, i}+K_{\text {forest }} N_{ \pm, i}+\ldots} \\
& \frac{N_{ \pm, i}}{\cdots+\sum_{j} \beta_{j} A N_{\text {ions }} N_{ \pm, i}} \\
\tau= & \frac{1}{K_{\text {chem }}+C S+K_{\text {forest }}+\sum_{j} \beta_{j} N_{\text {ions }, j}}
\end{aligned}
$$

Depending on the compound and the prevailing conditions these individual terms of Eq. (10) on the right are of different strength: The charging of these small neutrals can be calculated with collision rates of $10^{-9}(1 \mathrm{~nm})-10^{-6} \mathrm{~cm}^{3} \mathrm{~s}^{-1}$ $(1 \mu \mathrm{m})$ (Seinfeld and Pandis, 1998) and ambient air ion concentrations of about $1000 \mathrm{~cm}^{-3}$. Ambient $C S$ values range from $9.0 \times 10^{-4} \mathrm{~s}^{-1}$ to $1.0 \times 10^{-2} \mathrm{~s}^{-1}$ (Dal Maso et al., 2005). Finally the chemical destruction differs strongly between different compounds and will be the major term for very short lived (few seconds or less) compounds.

The integration over the lifetime $\tau$ of the compounds to be ionized is:

$$
\int_{N_{ \pm, i}(0)}^{N_{ \pm, i}(\tau)} \frac{d N_{ \pm, i}}{\sum_{j} \beta_{j} A N_{\mathrm{ions}, j} N_{0}-S \cdot N_{ \pm, i}}=\int_{0}^{\tau} d t
$$

For easier handling, we abbreviated the sink terms $S$ in the denominator:

$S=K_{\text {chem }}+C S+K_{\text {forest }}+\sum_{j} \beta_{j} A N_{\text {ions }, j}$

However, note that the recombination term $\left(\operatorname{Rec}=\sum_{j} \beta_{j} A N_{\text {ions }, j} \cdot N_{ \pm, i}\right)$ for the size range investigated was found by Tammet et al. (2006) to be $<13 \%$, with the largest value at the surface, which is about half of the forest sink and its value is decreasing above. It will mainly affect long-lived air ions. It has been omitted for ambient conditions in the following, but can be included here as well. In the general case we get

$$
\begin{aligned}
& \frac{1}{-S} \ln \left[\frac{\left(-S \cdot N_{ \pm, i}(\tau)+\sum_{j} \beta_{j} A N_{\text {ions }, j} N_{0}\right)}{\left(-S \cdot N_{ \pm, i}(0)+\sum_{j} \beta_{j} A N_{\text {ions }, j} N_{0}\right)}\right]=\tau \\
& \ln \left[\frac{\left(-S \cdot N_{ \pm, i}(\tau)+\sum_{j} \beta_{j} A N_{\text {ions }, j} N_{0}\right)}{\left(-S \cdot N_{ \pm, i}(0)+\sum_{j} \beta_{j} A N_{\text {ions }, j} N_{0}\right)}\right]=-S \tau \\
& \frac{\left(-S \cdot N_{ \pm, i}(\tau)+\sum_{j} \beta_{j} A N_{\text {ions }, j} N_{0}\right)}{\left(-S \cdot N_{ \pm, i}(0)+\sum_{j} \beta_{j} A N_{\text {ions }, j} N_{0}\right)}=e^{-S \tau} \\
& -S \cdot N_{ \pm, i}(\tau)+\sum_{j} \beta_{j} A N_{\text {ions }, j} N_{0}= \\
& \left(-S \cdot N_{ \pm, i}(0)+\sum_{j} \beta_{j} A N_{\text {ions }, j} N_{0}\right) \cdot e^{-S \tau} \\
& \sum_{j} \beta_{j} A N_{\text {ions }, j} N_{0} \\
& N_{ \pm, i}(\tau)+\frac{-S}{2}=
\end{aligned}
$$




$$
\begin{gathered}
\left(N_{ \pm, i}(0)+\frac{\sum_{j} \beta_{j} A N_{\text {ions }, j} N_{0}}{-S}\right) \cdot e^{-S \tau} \\
N_{ \pm, i}(\tau)=N_{ \pm, i}(0) e^{-\left(K_{\text {chem }}+C S+K_{\text {forest }}+\operatorname{Rec}\right) \tau} \\
+\frac{\sum_{j} \beta_{j} A N_{\text {ions }, j} N_{0}}{K_{\text {chem }}+C S+K_{\text {forest }}+\operatorname{Rec}} \\
\cdot\left(1-e^{-\left(K_{\text {chem }}+C S+K_{\text {forest }}+\operatorname{Rec}\right) \tau}\right)
\end{gathered}
$$

Now we consider the charged fraction $f_{\text {charged }, i}$ of molecules, clusters or particles in that size section. It is obtained by dividing the charged number concentration by the neutrals one in the corresponding size or mobility section. Assuming that there are no charges in size section $i$ at time $0\left(N_{ \pm, i}=0\right)$, the charged fraction $f_{\text {charged }, i}$ is given by

$$
\begin{aligned}
f_{\text {charged }, i}= & \frac{N_{ \pm, i}(\tau)}{N_{0}+N_{ \pm, i}} \\
\approx & \frac{N_{ \pm, i}(\tau)}{N_{0}} \\
f_{\text {charged }, i} \approx & \frac{\sum_{j} \beta_{j} A N_{\text {ions }, j}}{K_{\text {chem }}+C S+K_{\text {forest }}+\operatorname{Rec}} \\
& \cdot\left(1-e^{-\left(K_{\text {chem }}+C S+K_{\text {forest }}+R e c\right) \tau}\right)
\end{aligned}
$$

This equation relates the charged fraction to the collision rate of the neutrals with ambient air ions, to the neutrals lifetime as well as to the source strength of the neutrals. Since the fraction of charged molecules, clusters or particles below $1 \mathrm{~nm}$ in diameter is fairly low, we can approximate the sum of neutrals and air ions in the section by the concentration of the neutrals only. For the special case of unipolar charging inside a charger (high ion concentrations) the sink term can be approximated by "Rec" only and Eq. (21) becomes $1-\mathrm{e}^{-\mathrm{Rec} \cdot \tau}=1-\mathrm{e}^{-\sum_{j} \beta_{j} A \cdot N_{\text {ions }, j} \tau}$ as given e.g. in Friedlander (2000) for unipolar charging of nano-particles.

In case of the "real" atmosphere, the recombination term was neglected (see above) and thus the equation simplifies to:

$$
\begin{aligned}
f_{\text {charged }, i}^{\text {atmos }}= & \frac{\sum_{j} \beta_{j} A N_{\text {ions }, j}}{K_{\text {chem }}+C S+K_{\text {forest }}} \\
& \cdot\left(1-e^{-\left(K_{\text {chem }}+C S+K_{\text {forest }}\right) \tau}\right)
\end{aligned}
$$

Next, we can consider the charged fraction for conditions found at the measurement site in Hyytiälä. The collision frequencies $\beta_{j}$ at different sizes can be obtained from Eq. (3). In analogy to the CS approach for non-volatile trace gases, we can formulate an ionic condensation sink $C S^{*}$ for air ions at size $i$ by taking into account the enhancement factor $A$ and the fraction $\frac{N_{\text {ions }, i}}{N_{i}}$ :

$$
C S=2 \pi \int_{0}^{\infty} D_{1} d_{p} \beta_{M}\left(d_{p}\right) n\left(d_{p}\right) d d_{p}
$$

$$
\begin{aligned}
& =2 \pi \sum_{j} D_{1, i} \beta_{M, j} d_{p, j} N_{j} \\
& =\sum_{j} \beta_{j} N_{j} \\
C S^{*} & =\sum_{j}\left(\beta_{j} N_{j} \cdot A_{j} \frac{N_{\text {ions }, j}}{N_{j}}\right) \\
& \approx \sum_{j} \beta_{j} N_{j} \frac{N_{\text {ions }, j}}{N_{j}} \cdot A \\
C S^{*} & \approx C S \times A \cdot \frac{N_{\text {ions }}}{N}
\end{aligned}
$$

The relation of $C S$ and $C S^{*}$ depends on the distribution of the air ions with size and the polarization of the neutral, i.e. if it displays a dipole behaviour or a totally neutral one. Particles are known to be charged most efficiently at larger sizes $\left(d_{p}>20 \mathrm{~nm}\right.$, Seinfeld and Pandis, 1998) and much less at smaller size ranges. Despite this, there is a second maximum of air ions at molecular level competing, when taking into account the number concentration of charged molecules and particles. In their study on air ion sinks Tammet et al. (2006) found that the highest sink (65-69\%) is caused by ambient aerosol particles. Thus, the present air ions are mainly attached to aerosol particles. The maximum of the particle size distribution at Hyytiälä is usually located between 50 and $150 \mathrm{~nm}$ in diameter, in which $\approx 40 \%$ of the aerosol particles carry one and about $20 \%$ two charges. For the reasonable assumption that for collisions with a singly charged aerosol particle the colliding molecule will stick to the surface by electrostatic forces, we take into account the doubly charged particles only. In that case the polarity of both, the molecule and the particle is similar after "stealing" one of both charges by the colliding molecule. Hence, it is repulsive and easier for the newly charged molecule to "escape". However, if the ionized molecule is of very low volatility, it will most likely stick to the surface and probably undergo chemical reactions. Only non saturated compounds will allow this process to occur.

The opposite is true for a non-saturated compound, which is accepting ("steeling") one charge of the doubly charged aerosol particles and departs afterwards because of the repulsive force between both charges. In this case, the collision rate of neutrals between 0.56 and $0.75 \mathrm{~nm}$ with ambient air ions $\left(C S^{*}\right)$ can be approximated by $0.2 \cdot C S$ (double charged aerosols), if the neutral has no polarity $(A=1)$, since (a) the maximum of both, the condensation sink of neutral particles and the condensation sink of charged particles occurs at the same size. Hence, depending on the different sink term strengths either the $C S$ or the chemical destruction are the major processes determining the charged fraction: If the compound is very short lived $(\tau<1 \mathrm{~s})$, the chemical destruction dominates the charging process. For long-lived compounds $(\tau>100)$ the charging state of the preexisting aerosol particles and the forest sink do. For mediumlived compounds all processes contribute and will affect the 


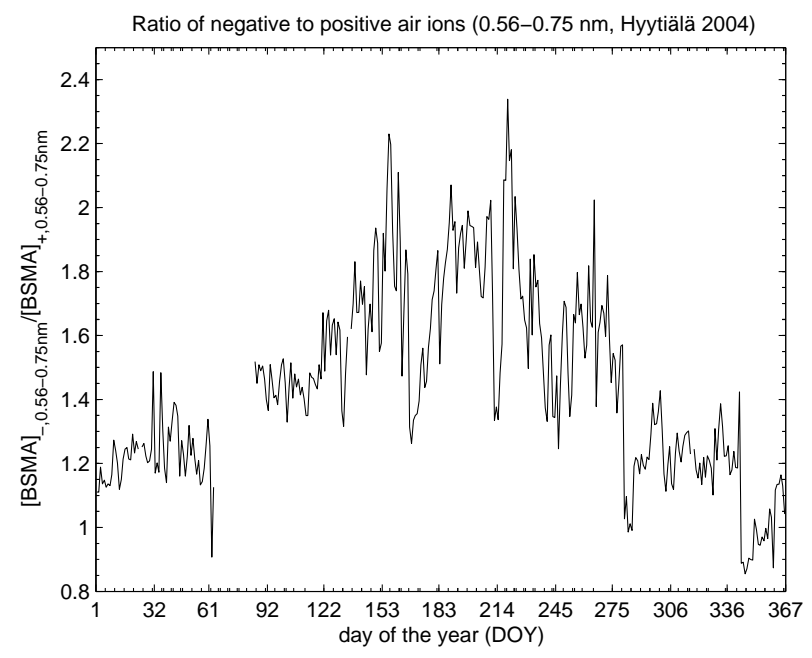

Fig. 3. Daily averaged ratio of negative to positive air ions measured in the second section with the BSMA between 0.56 and $0.75 \mathrm{~nm}$ mobility diameter as a function of the day of the year. A maximum of about 1.8 can be observed during summer and a minimum close to unity during winter.

charging state. A typical $C S$ value in the absence of polluted air masses is $2.5 \times 10^{-3} \mathrm{~s}^{-1}$ and thus about 1.5 times the forest sink term.

$$
\begin{aligned}
f_{\text {charged }, i}^{\text {atmos }}= & \frac{C S^{*}}{C S+K_{\text {chem }}+K_{\text {forest }}} \\
& \cdot\left(1-e^{-\left(C S+K_{\text {chem }}+K_{\text {forest }}\right) \tau}\right) \\
f_{\text {charged,long }}^{\text {atmos }} \approx & 0.13 \cdot\left(1-e^{-\left(C S+K_{\text {chem }}+K_{\text {forest }}\right) \tau}\right) \\
f_{\text {charged, short }}^{\text {atmos }} \approx & \frac{0.2 \cdot C S}{K_{\text {chem }}} \\
& \cdot\left(1-e^{-\mathrm{K}_{\text {chem }} \cdot \tau}\right) \\
\approx & \frac{0.2 \cdot C S}{\mathrm{~K}_{\text {chem }}} \cdot 0.63
\end{aligned}
$$

Although an expression for the charged fraction is now obtained, one problem remains: We need to know the identity of the ambient ions, their ambient lifetimes and their polarity. For thermodynamically stable clusters (chemically long-lived) and small particles this is given by the reciprocal condensation sink $C S$ and the forest sink $K_{\text {forest }}$ as the major sink processes. For single molecules this becomes different, depending on their chemical reactivity. For long lived compounds $\left(\tau_{\text {chem }} \gg \mathrm{CS}^{-1}\right)$ such as acids (organic and inorganic), aldehydes, alcohols, the situation is similar to clusters and particles. However, for short lived compounds $\left(\tau_{\text {chem }} \ll \mathrm{CS}^{-1}\right)$, e.g. radicals this becomes essentially dependent on the chemical lifetime.

For the aim of this study to figure out the chemical nature of the air ions in the size distribution maximum section there is a need to distinguish between both possible candidate groups: long-lived, i.e. thermodynamically stable clusters or unreactive molecules, and short-lived compounds. For this purpose we focus on the ratio of negative to positive ions in the size section between 0.56 and $0.75 \mathrm{~nm}$ in diameter. If the compounds are long lived such as sulphuric acid and the sink can be approximated by $C S^{*}$, the ratio of negative to positive charged air ions in a section is independent of time and season, if $C S$ is similar, since $C S$ impacts on both polarities in a similar way. Even the difference in electron and proton affinities will have a smaller impact, if both allow attachment of the charge. By contrast, if the ionized compounds are short lived and the slightly higher mobility of negative ions is taken into account, the change in lifetime due to an increased concentration of a destroying agent will affect the ratio significantly. In this context it should be noted that we assumed the source of the air ions in the size section between 0.56 and $0.75 \mathrm{~nm}$ in diameter to be similar throughout the year. This issue will be discussed later on.

If a long-lived neutral has the same affinity for accepting both charges, this ratio is expected to be unity for equilibrium conditions. In detail, if any neutral molecule, cluster or particle is sufficiently long present in the atmosphere, it will achieve its steady-state charged fraction, which depends on the neutrals size and its ability to accept charges (electron and proton affinity). Now we investigate the ratio of negative to positively charged molecules, clusters or particles in the section of maximum air ion concentrations between 0.56 and $0.75 \mathrm{~nm}$ in "Tammet" diameter (Tammet, 1995) (second size section considered) using BSMA data. The ratio can be deduced from the equations beforehand. In the following this is shown for a single type of neutrals $\left(N_{0}\right)$, but it can be done for the sum of all types as well:

$$
\begin{aligned}
\frac{N_{\text {ions }, i, \text { neg }}}{N_{\text {ions }, i, \text { pos }}} & =\frac{N_{0} \cdot f_{\text {charged }, i \text {, neg }}}{N_{0} \cdot f_{\text {charged }, i, \text { pos }}} \\
& =\frac{\sum_{j} \beta_{j} A_{j} N_{\text {ions }, j, \text { neg }}}{\sum_{j} \beta_{j} A_{j} N_{\text {ions }, j, \text { pos }}} \\
\frac{N_{\text {ions }, i, \text { neg }}}{N_{\text {ions }, i, \text { pos }}} & \approx \frac{\sum_{j} \beta_{j} N_{\text {ions }, j, \text { neg }}}{\sum_{j} \beta_{j} N_{\text {ions }, j, \text { pos }}}
\end{aligned}
$$

The ratio obtained from measurements is shown in Fig. 3 . Interestingly, the equilibrium is not achieved in here, but a clear maximum close to 2 can be observed during summer time, when chemical oxidation and reactivity is highest. By contrast, the equilibrium between negatively and positively charged ions is close to be reached during winter with 1.1.

One cause for the higher abundance of negative air ions is the on average $30-40 \%$ higher mobility of negative air ions (Israël, 1970). This causes a higher collision frequency of negatively charged ions with the neutral compared to the positive ions and thus, causing a higher abundance of negative 
air ions in the case of short lived compounds, clusters and particles, i.e. the maximum ratio in Eq. (34) to be expected is between 1.3-1.4. For longer lived ones, the effect vanishes, in case they are able to accept both charges. Hence, the behaviour of the ratio shown cannot be explained by the variation of CS and the higher mobility of negative ions only. Although $C S$ is on average slightly higher during summer, similar values are obtained occasionally during the other seasons all well. Therefore, the ratio cannot be caused predominantly by long-lived compounds. Otherwise, the ratio should scatter similar throughout the year.

The unexpected behaviour must originate by a short lifetime $\tau$ of the major neutrals to be charged in this size range. This is obvious from the description of the charged fraction and of the ratio in Eqs. (22) and (34). It can be explained this way: The longer any neutral resides in the atmosphere, the longer is the collision time with ambient ions and the more this effect decreases, finally reaching the steady-state conditions. On the contrary, for quite short lived compounds, i.e. of some seconds or less, this effect becomes evident. The shorter the lifetime of the neutrals for example caused by subsequent chemical reactions, the more the elevated collision rate of negative ions becomes obvious. Hence, we are looking for a rather short lived compound ( $\tau_{\text {chem }}$ of a few seconds or less) in order to achieve the measured ratio of charges. Otherwise, the neutrals must display a rather strong dipolar behaviour, which is not considered in here.

Finally, the assumption of similar sources of air ions in the size section studied needs to be discussed, since this could be a mixture of several sources, i.e. more than the proposed one with different characteristics throughout the year. However, the major change in the chemical composition of the atmosphere at the site is caused by increased biogenic VOC and water vapour concentration during the warm summer period as well as by the increased pollution of the air masses, transported towards the station. By contrast, $\mathrm{SO}_{2}$ and $\mathrm{NO}_{\mathrm{x}}$ species are elevated during winter because of the reduced solar radiation and the related photochemistry. As mentioned before, the stronger the pollution, the higher the aerosol burden of the atmosphere gets, causing the reduction of air ions due to the strong aerosol sink at larger sizes. We will investigate the impact of sulphuric and nitric acid in Sect. 5.6.2.

\subsection{Mass of the compound}

The compound, which we are looking for, needs to fulfil certain criteria: (i) its molecular mass should be located within the expected range and (ii) it should have a sufficiently high affinity to accept electric charges offered by ambient ions. Although we did rough estimates on the possible mass of the compounds previously, there is an experimental semiempirical relationship between the molar mass and the ion mobility, which has the benefit of being independent on the density, which is critical to define for a couple of molecules or less. This relationship is given by Tammet (1998), which is based on experimental data by Kilpatrick (1971). The molar mass of interest can be calculated using

$$
\begin{aligned}
Z_{e l} & =\left(\frac{1200 \frac{\mathrm{g}}{\mathrm{mol}}}{m_{\text {ion }}}\right)^{\frac{1}{3}}-0.2 \frac{\mathrm{cm}^{2}}{V \cdot s} \\
m_{\text {ion }} & =\left(\frac{1200 \frac{\mathrm{g}}{\mathrm{mol}}}{\left(Z_{e l}-0.2 \frac{\mathrm{cm}^{2}}{V \cdot s}\right)^{3}}\right)
\end{aligned}
$$

For this purpose we used the lower and upper mobility of the second mobility section. Since the section mobility limits were adjusted to fit the fixed mobility diameter range with variations in temperature and pressure, the lower limit mobility varied between 1.42 and $1.58 \mathrm{~cm}^{2} \mathrm{~V}^{-1} \mathrm{~s}^{-1}$. The corresponding upper limit mobility changed ranged from 1.9 (winter) to $2.1 \mathrm{~cm}^{2} \mathrm{~V}^{-1} \mathrm{~s}^{-1}$ (summer). The relationship of mass and mobility (Eq. 36) results in: 244 to $660 \mathrm{~g} \mathrm{~mol}^{-1}$ in winter and 174 to $457 \mathrm{~g} \mathrm{~mol}^{-1}$ during summer. These mass ranges are significantly larger as calculated by the simple approach above and as single sulphuric acid molecules. However it might include clusters of several molecules containing sulphuric acid hydrates. These clusters can include for instance five water molecules as well as sulphuric acid hydrates and ammonia, which is highest during summer. On the other hand sulphuric acid might already stick to the charged aerosol particle because of its low volatility when 'stealing' the charge. Additionally, these compounds or clusters are long-lived, contradicting the observations made before. This more accurate mass range is mainly occupied by single organic molecules or further molecular clusters (see for example Perkins et al., 1984, and Eisele and Tanner, 1990). It has to be taken into account that the larger the compound or cluster the less volatile it will be and the less will get or stay in the gas-phase. The most likely organic molecules at the site are of biogenic origin. Because of its necessary short lifetime of a few seconds or less, its molar mass and the seasonal pattern of the charging ratio of negative and positive air ions, we suggest that the major source for air ions in maximum section is the stabilised Criegee intermediate or biradical (Criegee, 1975) formed in the ozone reaction of biogenic sesquiterpenes.

Its molecular mass is $252 \mathrm{~g} \mathrm{~mol}^{-1}$, which is situated inside the boundaries throughout the entire year. However, similar structured Criegee intermediates, derived from monoterpene ozone reactions, are of smaller size (mass $=184 \mathrm{~g} \mathrm{~mol}^{-1}$ ), but could contribute during the warm period in summer as well. Their effect will be investigated in Sect. 5.6.1. Other suitable candidates such as carboxylic acids, carbonyl compounds, organic nitrates and hydroperoxides are expected to have a lifetime much too long for causing the observations. Even the lifetime of reactive organic peroxy radicals $\left(\mathrm{RO}_{2}\right)$ stay in the gas-phase for tenths of seconds. Their effect could arise due to a pronounced affinity for electrons only.

Thus, we need to investigate the electron and proton affinities of possible compounds to contribute to ion formation in 
Table 1. List of different organic organic compound classes investigated in earlier studies and their proton and electron affinities (Kauppila et al., 2002).

\begin{tabular}{lcc}
\hline $\begin{array}{l}\text { Compound/coumpound } \\
\text { class }\end{array}$ & $\begin{array}{c}\text { Proton affinity } \\
{\left[\mathrm{kJ} \mathrm{mol}^{-1}\right]}\end{array}$ & $\begin{array}{c}\text { Electron affinity } \\
{[\mathrm{eV}]}\end{array}$ \\
\hline acids (e.g. acetic acid) & 783.7 & n.a. \\
alcohols (methanol) & 754.3 & n.a. \\
aldehydes (e.g. HCHO) & n.a. & 0.65 \\
alkenes (e.g. toluene) & 784.0 & $0.55-0.7$ \\
ketones (e.g. 2,3-butanedione) & n.a. & $0.69 \pm 0.1$ \\
\hline water & 691.0 & n.a. \\
\hline $\mathrm{HO}_{2}$ & n.a. & 1.078 \\
benzyl radical & 831.4 & 0.912 \\
\hline
\end{tabular}

that section in order to seek for support or contradiction for the suggestion of stabilised Criegee biradicals.

\subsection{Electron and proton affinity}

As mentioned already in Sect. 2 there is a need not only for a collision of neutrals with ambient air ions to become charged but also to have a certain electron or proton affinity to take over the accepted charge by the collision partner. When there is a molecule aiming to receive a charge and an aerosol particle carrying it, the electron or proton affinity of both compounds or compound mixtures determines, if a charge transfer is plausible. If the required energy for separating charge and aerosol particle is larger than the one gained by attachment to the molecule (affinity), the transfer will not occur.

In detail, the electron and proton affinity describes the energy change in case of adding an electron or a positive charge to a neutral. A switch of the charge from the aerosol to the gaseous molecule only occurs, if the affinity of the molecule to get the charge is higher than the one of the aerosol mixture to which it is attached. High electron affinities (release of energies) are found for the atomic groups VIA (oxygen and sulfur) and VIIA (fluorine, chlorine, bromine and sulphur) with the highest for fluorine and oxygen. This behaviour changes remarkably for different molecules and molecular configurations. For example some species with hydrogen atoms strongly favor positive charges (e.g. water), while others favor negative charges (e.g. OH) (Atkins and de Paula, 2002). Therefore, it is essential to know, which compound is able to fulfill the requirements outlined above.

For this purpose selected organic compound classes, which are available in literature, are given in Table 1. The higher the oxidation degree (inclusion of oxygen atoms in the structure) the larger the adiabatic electron affinity. Furthermore, radicals are preferred because of their electron configuration over stable compounds. This has been found for inorganic compounds as well: Viggiano et al. (1980) reported very high electron affinities for $\mathrm{HSO}_{4}$ of $4.5 \mathrm{eV}$ and David-

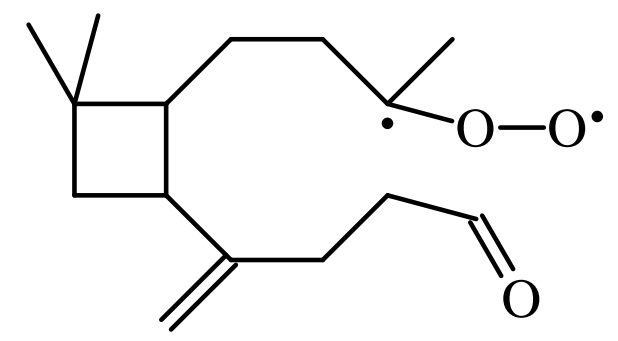

Fig. 4. Structure of one stabilised Criegee biradical from $\beta$-caryophyllene.

son et al. (1977) for the nitrate radical $\left(\mathrm{NO}_{3}\right)$ of $4.01 \mathrm{eV}$. Similar values were given for the corresponding clusters formed with sulphuric or nitric acid (Davidson et al., 1977; Ferguson and Arnold, 1981).

Besides this, we have calculated the electron and proton affinities of the most stable Criegee intermediate (Criegee, 1975) (Fig. 4) formed in the ozonolysis of $\beta$-caryophyllene using the Gaussian 03 program suite (Frisch et al., 2004). First, we optimized the geometry of the two possible Criegee biradicals formed in the ozonolysis process (labelled primary and secondary depending on the location of the COO- group) using the UB3LYP quantum chemical method (Becke, 1993; Lee et al., 1988) with the 6-31+G(d,p) basis set (Please find a glossary about all used quantum chemistry abbreviations in the Appendix A). The secondary isomer was found to be more stable by $21.8 \mathrm{~kJ} \mathrm{~mol}^{-1}$, probably due to a better stabilization of the $\mathrm{COO}$ moiety by the adjacent alkyl groups. Hence, all following computations were carried out on the secondary isomer only.

Next, the geometries of the doublet anion and the protonated singlet cation (with the proton added to the -COOgroup to form a peroxide structure) were optimized at the UB3LYP/6-31+G(d,p) level, and the harmonic vibrational frequencies were computed for the neutral structure and both the ions. The convergence limits for the neutral molecule and the protonated cation were $3 \times 10^{-4}, 4.5 \times 10^{-4}, 1.2 \times 10^{-3}$ and $1.8 \times 10^{-3}$ atomic units (a.u.) for the root-mean-square (RMS) force, maximum force, RMS displacement and maximum displacement, respectively. The potential surface for the anion was extremely flat, and the above convergence criteria for the atomic displacements could not be met within 250 optimization steps (starting from the neutral geometry). Nevertheless, the anionic structure used in the subsequent calculations was converged to within $2.0 \times 10^{-6}$ and $3.2 \times 10^{-6}$ a.u. for the RMS and maximum forces, respectively. The convergence criteria with respect to the electronic energy in the SCF step was $10^{-6}$ a.u. in all calculations.

Next, single-point energy calculations were performed at the UB3LYP/6-31+G(d,p) geometries using the UB3LYP method with the larger aug-cc-pVDZ and 6-311++G(d,p) basis sets. The electron and proton affinities could now be 
Table 2. Electron affinities calculated for the secondary sCI formed in the ozonolysis of $\beta$-caryophyllene using a variety of methods. All geometries have been optimized at the UB3LYP/6-31+G(d,p) level.

\begin{tabular}{lcccc}
\hline Level of electronic energy calculation & $\begin{array}{c}\text { vertical electron } \\
\text { affinity } \\
{\left[\mathrm{kJ} \mathrm{mol}^{-1}\right]([\mathrm{eV}])}\end{array}$ & $\begin{array}{c}\text { adiabatic electron } \\
\text { affinity } \\
{\left[\mathrm{kJ} \mathrm{mol}^{-1}\right],([\mathrm{eV}])}\end{array}$ & $\begin{array}{c}\text { Zero-point energy } \\
\text { correction } \\
{\left[\mathrm{kJ} \mathrm{mol}^{-1}\right],([\mathrm{eV}])}\end{array}$ & $\begin{array}{c}\text { Thermal enthalpy } \\
\text { correction at } 298 \mathrm{~K} \\
{\left[\mathrm{~kJ} \mathrm{~mol}^{-1}\right],([\mathrm{eV}])}\end{array}$ \\
\hline UB3LYP/6-31+G(d,p) & $15.15(0.16)$ & $38.43(0.40)$ & $12.39(0.13)$ & $-1.63(-0.017)$ \\
UB3LYP/6-311++G(d,p) & $24.95(0.26)$ & $41.94(0.43)$ & - & - \\
UB3LYP/aug-cc-pVDZ & $22.56(0.23)$ & $40.60(0.42)$ & - & - \\
OVGF(Frozen-Core)/6-31+G(d,p) & $92.39(0.96)$ & - & - & - \\
\hline
\end{tabular}

calculated simply as the energy difference between the ionic and neutral species, with the sign convention chosen so that positive values correspond to favourable electron or proton addition reactions. Both the vertical electron affinity, which corresponds to the energy difference between the anion and the neutral molecule calculated at the geometry of the latter, and the adiabatic electron affinity, which contain also the relaxation energy of the anion, was calculated. Note that experimentally measured electron affinities are adiabatic.

Since the reliability of density functional methods such as UB3LYP for treating biradical and radical species is questionable, we also calculated the vertical electron affinity of the sCI using the advanced OVGF (Outer Valence Green's Function) method (Zakrzewski and Ortiz, 1995; von Niessen et al., 1984) with the $6-31+\mathrm{G}(\mathrm{d}, \mathrm{p})$ basis set and the frozen core approximation. The UB3LYP electron affinities correspond to energy differences, and are therefore prone to errors arising from the differences in the quality of description of the electronic structure of the radical anion and the biradical neutral molecule. In contrast, the OVGF electron affinity is calculated using direct electron propagator methods which are not vulnerable to differences in the quality of the neutral and ionic wave functions. For full details on the theory behind the OVGF calculations see the corresponding references. The results of the electron affinity calculations are given in Table 2.

From the results shown in the table it can be seen that the electron addition reaction is energetically favourable at all levels of theory used, and that the more advanced methods yield larger electron affinities than the original UB3LYP/6$31+\mathrm{G}(\mathrm{d}, \mathrm{p})$ calculation. In particular, the OVGF vertical electron affinity (which should be considered inherently more reliable as described above) is almost four times larger than the corresponding UB3LYP/aug-cc-pVDZ and UB3LYP/6$311++\mathrm{G}(\mathrm{d}, \mathrm{p})$ values. It should be noted that the UB3LYP anion relaxation energies (i.e. the difference between adiabatic and vertical electron affinities) obtained using different basis sets differ less than the electron affinities themselves, and that the especially the relaxation energies obtained using the larger basis sets aug-cc-pVDZ and $6-311++G(d, p)$ are almost identical.
Adding the OVGF/6-31+G(d,p) vertical electron affinity, the UB3LYP/6-31+G(d,p) zero-point and thermal enthalpy corrections and the UB3LYP/aug-cc-pVDZ or UB3LYP/6$311++\mathrm{G}(\mathrm{d}, \mathrm{p})$ relaxation energy, we obtain a rough estimate of ca $120.1 \mathrm{~kJ} \mathrm{~mol}^{-1}(1.24 \mathrm{eV})$ for the "best-guess" adiabatic electron affinity.

The electronic energy component of the proton affinity was calculated to be $984.6 \mathrm{~kJ} \mathrm{~mol}^{-1}$ at the UB3LYP/6$31+\mathrm{G}(\mathrm{d}, \mathrm{p})$ level, with a zero-point energy correction of $-31.4 \mathrm{~kJ} \mathrm{~mol}^{-1}$ and a thermal enthaply correction of $+4.6 \mathrm{~kJ} \mathrm{~mol}^{-1}$ at $298 \mathrm{~K}$ (including both the thermal enthalpy difference of the cation and neutral molecule and the factor of $\left.\frac{3}{2} R T\right)$. Single-point energy calculations at the UB3LYP/augcc-pVDZ and UB3LYP/6-311++G(d,p) levels both yielded the slightly higher value of $986.6 \mathrm{~kJ} \mathrm{~mol}^{-1}$. Combining the UB3LYP/6-31+G(d,p) zero-point and thermal enthaply corrections with with the UB3LYP/6-311++G(d,p) or UB3LYP/aug-cc-pVDZ electronic energy changes, we obtain a "best-guess" value of $960.0 \mathrm{~kJ} \mathrm{~mol}^{-1}$ for the proton affinity.

To conclude, the stabilised Criegee biradical from $\beta$ caryophyllene ozonolysis is likely to participate in the charging process as suggested. Both, its electron affinity as well as its proton affinity, are sufficiently high because of its biradical character. This allows both charge types to attach to the neutral.

Furtheron, take into account the major constituents of the ambient aerosol particles between 50 and $150 \mathrm{~nm}$ in diameter. They are expected to be mainly organics. Minor contributions are expected of sulphuric acid (more contribution at smaller sizes) and of nitrate compounds, depending on the impact of pollution. This results in a competition among the organics and nitrate compounds for the charge. Charge affinities of different organic compounds (organic acids, carbonyl compounds, alcohols, alkanes and alkenes) to be expected in the ambient aerosol phase (Table 1) are lower than the ones of the stabilised Criegee intermediates. Nitric acid only has an electron affinity of $0.57 \mathrm{eV}$ and a proton affinity of $751.4 \frac{\mathrm{kJ}}{\mathrm{mol}}$ (CRC handbook, 1998) and is not able to compete with the Criegee biradical too. A similar situation can be found for other nitrogen containing compounds. Radical 
and further reactive species such as $\mathrm{OH}$ (electron affinity = $1.827 \mathrm{eV}$ ), $\mathrm{NO}_{3}$ and ozone (electron affinity $=2.1 \mathrm{eV}$ ) can compete. However, these are not within the mass range calculated. The only competitive partners for ambient ions are clusters, including radicals (see above). Consequently, if there is a stabilised Criegee intermediate colliding and competing with doubly charged aerosol particle constituents it will most likely take over the charge in case it is not a cluster with radical species.

Because of the seasonal behaviour in Fig. 3 and because of the required short ambient lifetime we assume that the charged compounds in the second section mainly consist of the stabilised Criegee intermediate (sCI) of the atmospheric oxidation of sesquiterpenes by ozone (Criegee, 1975) with a molar mass of $252 \mathrm{~g} \mathrm{~mol}^{-1}$.

Biogenic VOCs are known to be emitted as a response of the vegetation to stress factors such as temperature, draught, sun light and hazardous chemical species like ozone (Guenther et al., 1995; Hakola et al., 2006; Loreto et al., 2001). Their emission is highest during summer because of the elevated temperatures and the high water fluxes. In winter their emission is rather tiny, although terpenes have been found even in the winter time at Hyytiälä in significant amounts (Hakola et al., 2003). While monoterpenes are oxidized by $\mathrm{OH}, \mathrm{NO}_{3}$ andO $\mathrm{O}_{3}$ with lifetimes of several hours, sesquiterpenes are much more reactive especially towards ozone (Shu and Atkinson, 1995). The most abundant one is $\beta$-caryophyllene with an ozone reaction rate constant of $1.16 \times 10^{-14} \mathrm{~cm}^{3}$ molecule ${ }^{-1} \mathrm{~s}^{-1}$ (Shu and Atkinson, 1994). This results in an atmospheric lifetime of about 80-90 s, depending on the ambient ozone concentration. Because of their ambient concentration and the reaction speed, $\mathrm{OH}$ and $\mathrm{NO}_{3}$ do not contribute to more than $5 \%$ to the degradation of sesquiterpenes at the conditions investigated.

\subsection{Sesquiterpene-ozone reaction}

In the reaction of sesquiterpenes, i.e. $\beta$-caryophyllene (most predominant one in Hyytiälä), with ozone the latter adds to the internal carbon double bond, forming a primary ozonide. Next, this decomposes instantaneously to form the Criegee biradical. Most of this biradical stabilises, because the major alternative pathway, which forms $\mathrm{OH}$, is found to be of minor importance (yield $=6 \%$ ). This stabilised Criegee biradical reacts mainly with water vapour due to the high $\mathrm{H}_{2} \mathrm{O}$ concentration in the atmosphere (see scheme in Fig. 5). Assuming a reasonable reaction rate of $1.0 \times 10^{-17} \mathrm{~cm}^{3}$ molecule $\mathrm{e}^{-1} \mathrm{~s}^{-1}$ (Großmann, 1999), ambient chemical lifetimes of this biradical is varying between 0.3 and $1.5 \mathrm{~s}$ throughout the year with a minimum at highest water vapour concentrations during summer. This allows the deposition and condensation to be neglected in Eq. (10).

$$
\tau \approx \tau_{\text {chem }}=\frac{1}{k_{\mathrm{sCI}}^{\mathrm{H}_{2} \mathrm{O}} \cdot\left[\mathrm{H}_{2} \mathrm{O}\right]}
$$

An annual plot of this lifetime is shown in Fig. 6. For intercomparison the ratio of negative to positive air ions is displayed as well. An anticorrellation of ratio and lifetime is clearly visible.

\subsection{Other possible candidates}

But are there any further candidates to contribute to notable charging in this size section $(0.56-0.75 \mathrm{~nm})$ too? Two possible or suggested candidates would be (1) the stabilised Criegee biradical from ozone reactions with monoterpenes, emitted by the vegetation as well, and (2) sulphuric acid clusters (Kulmala et al., 2000; Eisele et al., 2006).

\subsubsection{Monoterpenes}

Monoterpenes are less reactive with respect to the atmospheric oxidants $\mathrm{OH}, \mathrm{NO}_{3}$ and $\mathrm{O}_{3}$ and the preferred one of these depends highly on the individual monoterpene structure. The most abundant ones at the forest site in Hyytiälä are $\alpha$-pinene, $\Delta^{3}$-carene and $\beta$-pinene (Hakola et al., 2003). They have atmospheric chemical lifetimes given as:

$$
\begin{aligned}
\tau_{\text {chem }} & =\frac{1}{K_{\mathrm{O}_{3}}+K_{\mathrm{OH}}+K_{\mathrm{NO}_{3}}} \\
& =\frac{1}{k_{\mathrm{O}_{3}}\left[\mathrm{O}_{3}\right]+k_{\mathrm{OH}}[\mathrm{OH}]+k_{\mathrm{NO}_{3}}\left[\mathrm{NO}_{3}\right]}
\end{aligned}
$$

Because of their different reactivities, ambient lifetimes of monoterpenes at Hyytiälä are calculated between $50 \mathrm{~min}$ (limonene) and $3 \mathrm{~h}$ ( $\beta$-pinene), assuming an ozone mixing ratio of $35 \mathrm{ppbv}$, an $[\mathrm{OH}]$ of $1.0 \times 10^{6} \frac{\text { molecules }}{\mathrm{cm}^{3}}$ and a $\left[\mathrm{NO}_{3}\right]$ concentration of $1.0 \times 10^{8} \frac{\text { molecules }}{\mathrm{cm}^{3}}$ (Table 3 ). An exception in here is camphene with a lifetime of a few days because of its extremely low reaction rate constant with ozone. Excluding camphene, the lifetime of the monoterpene mixture is thus about $2 \frac{1}{4} \mathrm{~h}$. This chemical lifetime is significantly longer and the stabilisation ratios of the considered monoterpenes within the ozone reaction are drastically smaller $(<30 \%)$ than for sesquiterpene-ozone reactions. Therefore, the production of the monoterpene stabilised Criegee biradicals is significantly lower. Nevertheless the destruction by the reaction of the stabilised Criegee biradicals with water vapour is similar in speed, resulting in identical lifetimes as calculated for the sesquiterpenes.

For calculating the contribution of monoterpenes to the charged air ions we considered the monoterpene mixture (Table 3) obtained by field measurements of Hakola et al. (2003) and used monoterpene emission simulations performed with the optimal stomata controlled model (Bäck et al., 2005) already used in Boy et al. (2005). From the same work we used calculated $\mathrm{OH}$ concentrations and boundary layer heights, obtained by sounding measurements at a site with a similar surface profile near by $(\approx 100 \mathrm{~km})$. Within this boundary height the emitted monoterpenes are assumed to be instantaneously diluted because of their long lifetime. Although it 

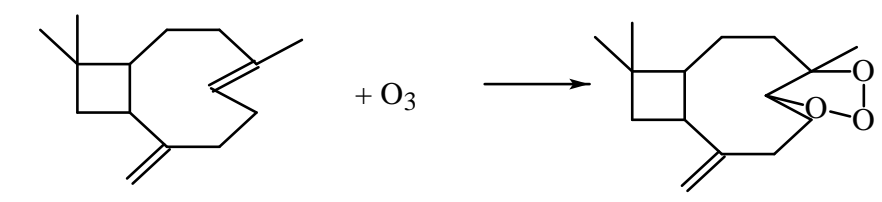

primary ozonide (pOZ)

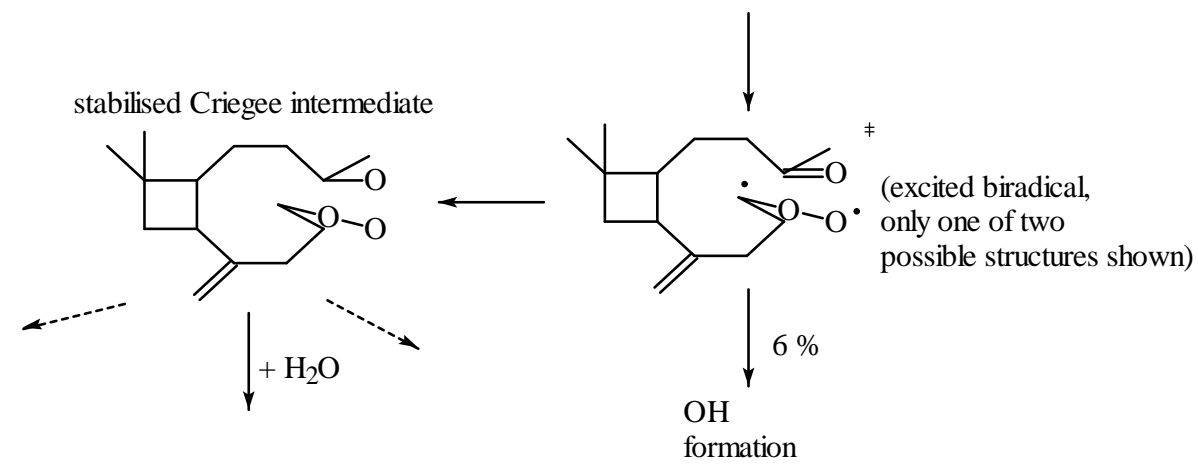

Fig. 5. Simplified oxidation scheme for the sesquiterpene $\beta$-caryophyllene with ozone. For simplicity one of both biradicals is shown only. However, both behave similar. In here the minor pathway $(<10 \%)$ forming an ester is omitted because of its usually minor importance.

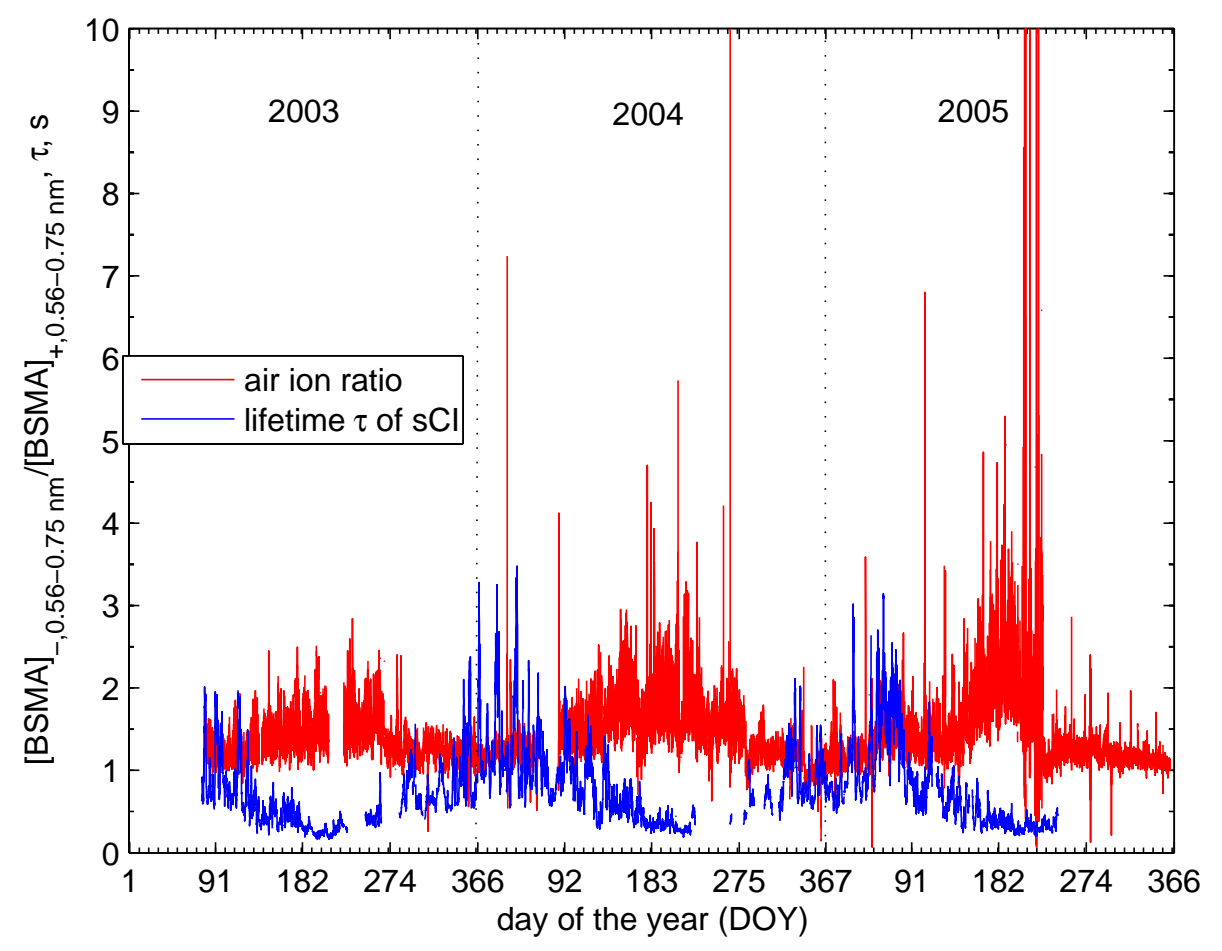

Fig. 6. Three years plots of the half hour averaged ratio of negative to positive air ions in the 2nd section compared to the lifetime of stabilised Criegee intermediates from sesquiterpene - ozone reactions. A clear anticorrellation between both is visible.

could be argued that local monoterpene concentrations can be significantly higher, the long lifetime compared to the shorter mixing time needs to be considered. Next, we can calculate the amount of air ions formed by stabilised Criegee intermediates in monoterpene ozone reactions using the mea- sured ozone and water vapour concentrations with a time resolution of $30 \mathrm{~min}$. For the charging ratio we applied Eq. 22. The results are shown in Fig. 7. Because of its slow reactivity and the low stabilisation ratio, the contribution is only visible in summer, when emissions are highest, but never 
Table 3. Individual monoterpene constituents, reaction rates (Atkinson et al., 2006), stabilisation rates (Atkinson et al., 2006; Geiger et al., 2002) and ambient monoterpene fraction at Hyytiälä extrapolated from Hakola et al. (2003).

\begin{tabular}{lcccccl}
\hline Monoterpene & $\left.\begin{array}{c}\mathrm{k}_{\mathrm{O}_{3}} \\
{\left[\mathrm{~cm}^{3} \text { molecule }\right.}\end{array} \mathrm{s}^{-1}\right]$ & $\left.\begin{array}{c}\mathrm{k}_{\mathrm{OH}} \\
{\left[\mathrm{cm}^{3} \text { molecule }\right.}\end{array} \mathrm{s}^{-1}\right]$ & $\begin{array}{c}\mathrm{k}_{\mathrm{NO}_{3}} \\
{\left[\mathrm{~cm}^{3} \text { molecule }^{-1} \mathrm{~s}^{-1}\right]}\end{array}$ & $\begin{array}{c}\text { stabilsation } \\
\text { fraction }\end{array}$ & $\begin{array}{c}\text { ambient } \\
\text { fraction }\end{array}$ & $\begin{array}{l}\text { lifetime } \\
{[\mathrm{h}]}\end{array}$ \\
\hline$\alpha-$ pinene & $8.66 \times 10^{-17}$ & $5.37 \times 10^{-11}$ & $6.16 \times 10^{-12}$ & $12.5 \%$ & $50 \%$ & 2.1 \\
$\Delta^{3}$-carene & $3.7 \times 10^{-17}$ & $8.8 \times 10^{-11}$ & $9.1 \times 10^{-12}$ & $0-6 \%$ & $27 \%$ & 2.3 \\
$\beta$-pinene & $1.5 \times 10^{-17}$ & $7.89 \times 10^{-11}$ & $2.51 \times 10^{-12}$ & $24.9 \%$ & $11 \%$ & 3.0 \\
camphene & $0.09 \times 10^{-17}$ & $5.3 \times 10^{-11}$ & $0.66 \times 10^{-12}$ & n.a. & $5 \%$ & 358.0 \\
limonene & $20 \times 10^{-17}$ & $17.1 \times 10^{-11}$ & $12.2 \times 10^{-12}$ & $23-57 \%$ & $4 \%$ & 0.9 \\
sabinene & $8.6 \times 10^{-17}$ & $11.7 \times 10^{-11}$ & $10 \times 10^{-12}$ & $33-75 \%$ & $3 \%$ & 1.5 \\
\hline
\end{tabular}

exceeds $5 \%$. Therefore, they cannot be assumed to be the predominant origin of the detected air ions. However, they can contribute to a minor extent and thus should be included if possible.

\subsubsection{Sulphuric acid and nitric acid clusters}

The second possibility includes (i) sulphuric acid clusters formed from sulphuric acid (atmospheric oxidation of $\mathrm{SO}_{2}$ by $\mathrm{OH}$ ), water vapour and ammonia and (ii) nitric acid (mainly oxidation of $\mathrm{NO}_{2}$ by $\mathrm{OH}$ ) clusters formed in a similar way. $\left(\mathrm{SO}_{2}\right.$ and $\mathrm{NO}_{2}$ are of anthropogenic origin and highest during the winter time, while the $\mathrm{OH}$ concentration is calculated to be highest during summertime. This is caused by the most intense sunlight (Boy et al., 2005), but is balanced by the high abundance of VOCs during that time, causing a rather steady $\mathrm{OH}$ daily maximum during the whole summertime. Sulphuric acid- and nitric acid-ion clusters have a atmospheric lifetime, which can be related to the condensation sink on particles and the sink of the forest canopy surfaces. The latter was found to be about $18-26 \%$ of the total sink compared to the major loss by aerosol particles of $65-69 \%$ (Tammet et al., 2006). The corresponding value of several hundred seconds disagrees with the results shown above, which require a sufficiently short lifetime of the neutrals to be charged. Also the seasonal concentration maxima of the acids only are expected to be rather constant from the start of May on until the end of August, disagreeing with the seasonal behaviour of the charging ratio in Fig. 3. In this case only the impact of ammonia could cause the seasonality. However, these clusters are assumed to be thermodynamically stable and consequently long-lived. For detailed investigations ammonia data would be required within the same time period, which is not available here.

For nitric acid with a smaller molar mass a cluster has to contain at least one nitric acid molecule and seven water molecules to exceed the lower mass limit.

These facts and especially the long lifetime of both acid derived clusters seem to contradict a dominant source of air ions in the size range between 0.56 and $0.75 \mathrm{~nm}$ in mobil- ity derived diameter. Otherwise they would determine the pattern of negative to positive air ions, yielding a constant ratio during late spring and early autumn. Consequently, the observations made like the minimum concentration during summer time between 0.56 and $0.75 \mathrm{~nm}$ seem to be explained best by the stabilised Criegee biradicals, which are destroyed most intense by the water vapour during summer, but not by sulphuric acid type clusters or something similar.

\section{Ambient sesquiterpene concentration estimate}

If we assume the ambient air ions in the section between 0.56 and $0.75 \mathrm{~nm}$ in diameter of both polarities to consist of stabilised Criegee intermediates from sesquiterpenes only (maximum approach), we gain the possibility to estimate the ambient concentration of sesquiterpenes. Applying steadystate conditions, which is reasonable for a compound with a lifetime of about one second, it follows:

$$
\begin{aligned}
& \text { source }=\sin \mathrm{k} \\
& \left(1-Y_{\mathrm{OH}}\right) \cdot k_{\text {sesqui }}^{\mathrm{O}_{3}} \cdot[\text { sesquiterpene }]\left[\mathrm{O}_{3}\right] \\
& =k_{s C I}^{\mathrm{H}_{2} \mathrm{O}}[s C I]\left[\mathrm{H}_{2} \mathrm{O}\right] \\
& 0.94 \cdot 1.16 \times 10^{-14} \frac{\mathrm{cm}^{3}}{\text { molecule s }}[\text { sesquiterpene }]\left[\mathrm{O}_{3}\right] \\
& =10^{-17} \frac{\mathrm{cm}^{3}}{\text { molecule } \mathrm{s}}[s \mathrm{CI}]\left[\mathrm{H}_{2} \mathrm{O}\right] \\
& {[\text { sesquiterpene }]=\frac{10^{-17} \frac{\mathrm{cm}^{3}}{\text { molecule s }}[s C I]\left[\mathrm{H}_{2} \mathrm{O}\right]}{0.94 \cdot 1.16 \times 10^{-14} \frac{\mathrm{cm}^{3}}{\text { molecule s }}\left[\mathrm{O}_{3}\right]}}
\end{aligned}
$$

In this set of Eqs. (41-43) $\mathrm{Y}_{\mathrm{OH}}$ is the $\mathrm{OH}$ yield, representing the second important reaction pathway (hydroperoxide channel) besides the stabilisation. Since the ester channel is usually of minor importance, we treat the stabilisation as the fraction is not progressing through the hydroperoxide channel. $\mathrm{k}_{\mathrm{i}}^{\mathrm{j}}$ are the different reaction rate constants of compound $i$ with $j$. In this context the source is the reaction of the sesquiterpene with ozone and the major sink, the reaction of the stabilised Criegee intermediate (sCI) with water vapour. 

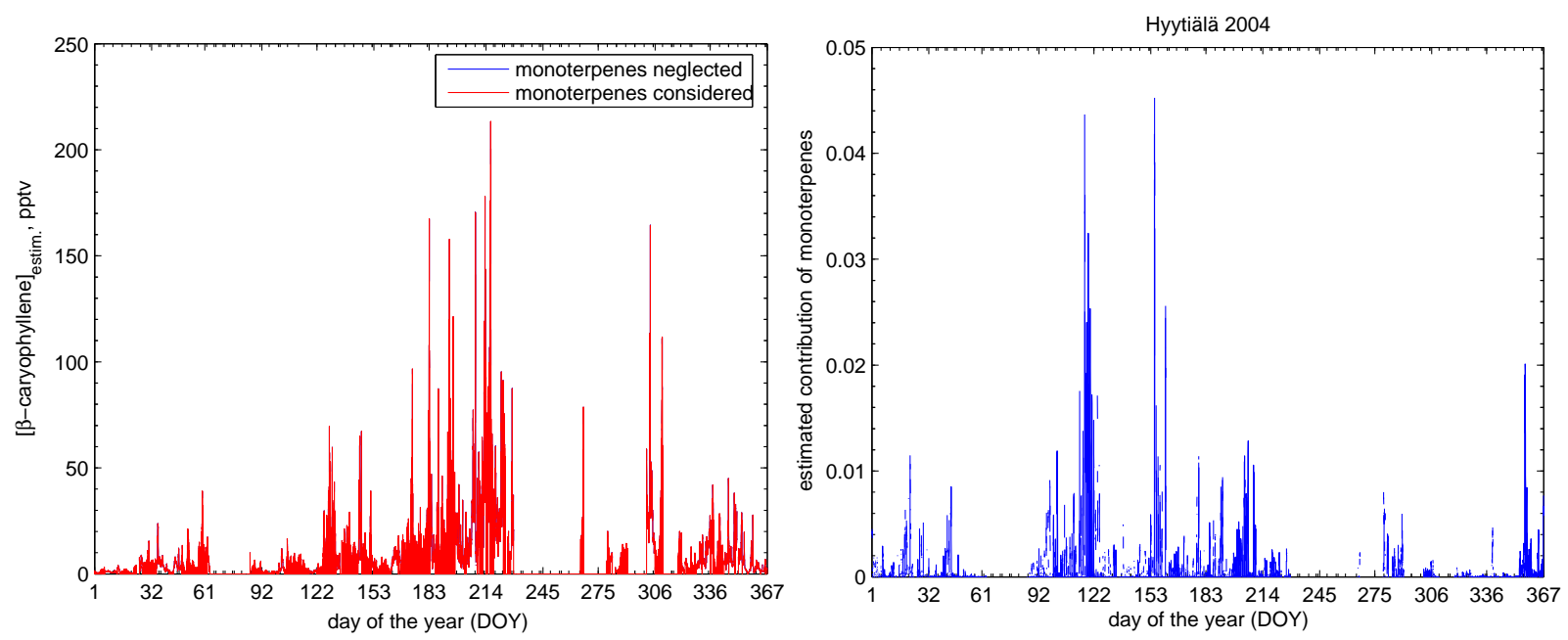

Fig. 7. Annual effect of monoterpenes on the calculated sesquiterpene derived stabilised Criegee biradicals. Shown on the left is in red the results neglecting the contribution of monoterpenes, in blue taking them into account. The right plot gives the relative effect of monoterpene consideration throughout the year. The relative contribution is always found to be less than $5 \%$.

When the charged fraction is known (see Fig. 8), the sCI concentration can be replaced by the concentration of air ions of both polarities in the maximum negative air ion section $(0.56-0.75 \mathrm{~nm})$ divided by the charged fraction. Consecutively, the maximum ambient sesquiterpene concentration at the inlet of the ion instrument can be calculated (maximum approach). The results for 2003-2005 are shown in Fig. 9 (left) and a detailed annual behaviour for 2004 on the right. Since the exact value of the reaction rate constant of the sCI with water vapour is not known yet, but estimated to be $1 \times 10^{-17} \mathrm{~cm}^{3}$ molecule ${ }^{-1} \mathrm{~s}^{-1}$ from laboratory studies (Großmann, 1999), we can estimate the impact of a different rate constant than used: Literature values are available in the range of $2 \times 10^{-19}-1 \times 10^{-15} \mathrm{~cm}^{3}$ molecule ${ }^{-1} \mathrm{~s}^{-1}$. From Eq. (43) it is apparent that the estimated sesquiterpene concentration depends linearly on rate constant. Hence, the estimated values could be 50 times lower or 100 times higher. However, both extremes seems to be rather unlikely and are not able to explain the hydrogen peroxide formation behaviour in the laboratory studies. The value of Großmann (1999) is rather centered in the literature range and seems to explain the formation and destruction of the formed $\mathrm{H}_{2} \mathrm{O}_{2}$ rather well. A value close within a factor of 3 of the one used might be reasonable. In this context detailed laboratory studies would be required for sesquiterpenes. Therefore, we are confident to use the value of $10^{-17} \mathrm{~cm}^{3}$ molecule ${ }^{-1} \mathrm{~s}^{-1}$ here.

Note that two exceptional days (15th and 29th were excluded from Fig. 9, because of the estimated high sesqterpene concentrations probably caused by wood burning close by. But these will be discussed briefly afterwards (Sect. 6.4).

For intercomparison we included emission measurements at shoot level during 2004 (Tarvainen et al., 2005; Hakola et al., 2006) in this plot. These emissions are given in the

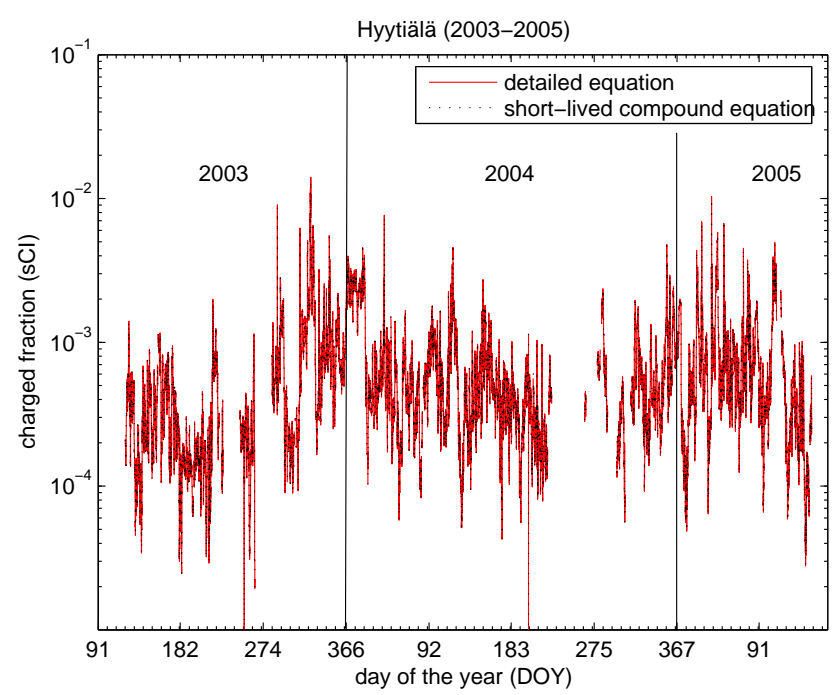

Fig. 8. Calculated charged fraction of stabilised Criegee intermediates between 2003 and 2005. For this both equations, i.e. the detailed Eq. (29) and the reduced Eq. (31) for short lived compounds are used. A clear seasonality is apparent.

units $n g \mathrm{~g}(\text { dry weight })^{-1} \mathrm{~h}^{-1}$. A good agreement is visible. With this an annual maximum of about 100 pptv is found during summer 2004 (Fig. 9 (right)), when biogenic VOC emissions are expected to be highest. By contrast the calculated concentration is minimum during winter as seen for ambient monoterpene concentrations by Hakola et al. (2003) If we would assume the emitted sesquiterpene molecules measured to be instantaneously mixed within the boundary layer, we would obtain on average values of about a third of the 

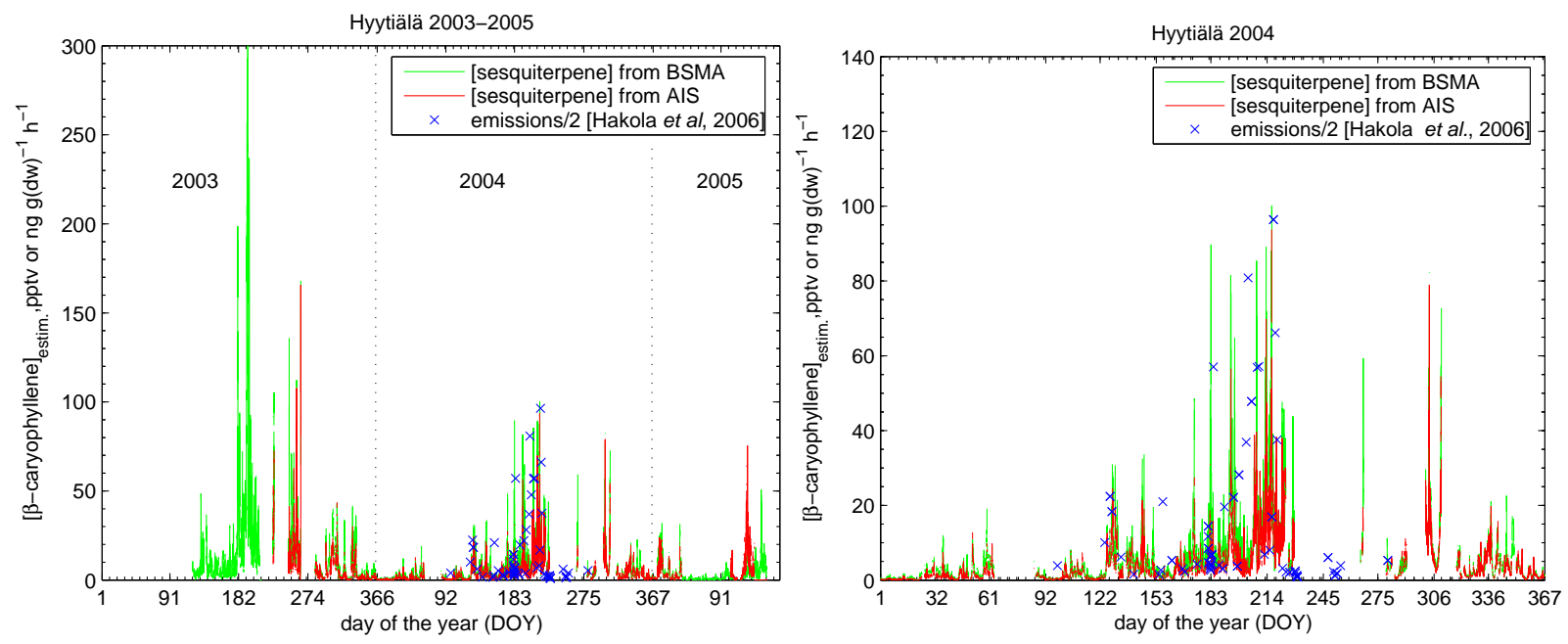

Fig. 9. (left) Calculated sesquiterpene concentrations for two years of data using both, the BSMA and the AIS dataset. For detailed intercomparison, the annual behaviour is shown for 2004 on the right. Available spot like shoot emission measurements of Hakola et al. (2006) are included in here in the units $\mathrm{ng} \mathrm{g}(\mathrm{dw})^{-1} \mathrm{~h}^{-1}$.

calculated values, depending on the boundary layer height. However, during the mixing process a significant fraction the short lived sesquiterpenes is destroyed already, so that they cannot be assumed to be well mixed but highest at the canopy level.

Please note in this context that the sampling of air ions took place about $2 \mathrm{~m}$ above the surface and not at the canopy level, where the maximum concentration is to be expected. Therefore, the emitted sesquiterpenes must have been transported previously, during which a notable fraction has been destroyed already. This approach is therefore dependent on the boundary layer vertical velocities and mixing to get the sesquiterpene molecules from the emission point towards the air ion instrument inlet. Currently available instruments have lower detection limits, i.e. amounts of a compound needed to exceed the noise level, of about $20 \mathrm{pptv}$ and more. Thus, no ambient sesquiterpene concentrations would be detected at the sampling point for air ions except in summer. By contrast these currently neglected amounts of sesquiterpenes will have a significant effect on ozone concentrations in the canopy, reducing ozone close to the vegetation surfaces and thus protect trees from harmful ozone stress and destruction (Loreto et al., 2001).

6.1 Sensitivity of the derived sesquiterpene concentration on the air ion fraction assumed

Since we have used only the so-called "maximum approach", assuming all air ions in the second size section to consist of sCIs, there is a need to check the impact of this assumption on the results obtained. Therefore, we have chosen three alternative assumptions for the sCI fraction of the air ions in the second section: (i) At equilibrium conditions (ratio neg- ative to positive ions equals unity, see Fig. 3), no sCIs are apparent. sCIs are only assumed to cause the excess of negative air ions ("overcharging", unreasonable because of the biradical structure). Furthermore, we assumed the "baseline" of "no contribution" of sCIs to ambient air ions to be at a charging ratio of negative to positive ions at 1.2 , only above 1.2. Finally, the maximum difference in charging ratio to be explained by the different mobility of negative and positive ions is 1.4. In case (iii) we assume that the higher concentration of negative ions can be explained up to 1.4 by the higher mobility of these and thus a higher formation rate, without taking into account any sCI. The intercomparison results for 2004 are shown in Fig. 10.

Table 4 summarizes the range of the different approaches. As it is already obvious from Fig. 10, the maximum and mean values decrease the higher the baseline in Fig. 3 is set. While this does not have notable input on the minimum values, the mean values drop by a factor of maximum 7 .

\subsection{Investigated air ions: clusters or single molecules?}

Above, we have treated the measured atmospheric air ions as charged single molecules by contrast to recent suggestions of ion clusters (Kulmala et al., 2000; Laakso et al., 2002). These recent studies base on the interaction of sulphuric acid, water and probably ammonia molecules in order to form new stable atmospheric clusters as a starting point of atmospheric new particle formation. None of the three molecules is able to fit in the amu range of the second size section investigated as a single molecule. Our assumption of charged single molecules will be discussed next.

Therefore we investigated the ratio of negative to positive air ions measured within the smallest six size bins. 
Table 4. Minumum, maximum and mean sesquiterpene volume mixing ratio values [pptv] during 2004 obtained for the four different cases given in the text. The seasons were defined as: ${ }^{a}$ March-May, ${ }^{b}$ June-August, ${ }^{c}$ September-November and ${ }^{\mathrm{d}}$ January-February. December was skipped in here because of the so-called "event-days", which would have affected the results significantly.

\begin{tabular}{|c|c|c|c|c|c|c|}
\hline Season & minimum & $\begin{array}{l}\text { maximum } \\
\text { approach } \\
\text { maximum }\end{array}$ & mean & minimum & $\begin{array}{r}\text { baseline } \\
\text { at } 1.0 \\
\text { maximum }\end{array}$ & mean \\
\hline spring $^{\mathrm{a}}$ & $0.1 \mathrm{pptv}$ & $33.6 \mathrm{pptv}$ & $3.3 \mathrm{pptv}$ & 0.18 pptv & $8.2 \mathrm{pptv}$ & $1.3 \mathrm{pptv}$ \\
\hline summer $^{\mathrm{b}}$ & $0.3 \mathrm{pptv}$ & $100.1 \mathrm{pptv}$ & $8.8 \mathrm{pptv}$ & 0.14 pptv & $38.1 \mathrm{pptv}$ & $2.4 \mathrm{pptv}$ \\
\hline autumn $^{\mathrm{c}}$ & $0.4 \mathrm{pptv}$ & $82.1 \mathrm{pptv}$ & $9.9 \mathrm{pptv}$ & $0.5 \mathrm{pptv}$ & 14.4 pptv & $4.8 \mathrm{pptv}$ \\
\hline winter ${ }^{\mathrm{d}}$ & $0.1 \mathrm{pptv}$ & 19.1 pptv & $1.9 \mathrm{pptv}$ & $0.4 \mathrm{pptv}$ & $3.7 \mathrm{pptv}$ & $1.7 \mathrm{pptv}$ \\
\hline Season & minimum & $\begin{array}{r}\text { baseline } \\
\text { at } 1.2 \\
\text { maximum }\end{array}$ & mean & minimum & $\begin{array}{r}\text { baseline } \\
\text { at } 1.4 \\
\text { maximum }\end{array}$ & mean \\
\hline spring $^{\mathrm{a}}$ & $0.1 \mathrm{pptv}$ & 5.7 pptv & 0.9 pptv & $0.1 \mathrm{pptv}$ & $3.4 \mathrm{pptv}$ & $0.5 \mathrm{pptv}$ \\
\hline summer $^{b}$ & $0.1 \mathrm{pptv}$ & $34.1 \mathrm{pptv}$ & $1.8 \mathrm{pptv}$ & $0.1 \mathrm{pptv}$ & 30.0 pptv & $1.8 \mathrm{pptv}$ \\
\hline autumn ${ }^{\mathrm{c}}$ & $0.3 \mathrm{pptv}$ & 9.9 pptv & $3.5 \mathrm{pptv}$ & $0.1 \mathrm{pptv}$ & $5.4 \mathrm{pptv}$ & $2.3 \mathrm{pptv}$ \\
\hline winter ${ }^{\mathrm{d}}$ & $0.3 \mathrm{pptv}$ & $2.9 \mathrm{pptv}$ & $1.3 \mathrm{pptv}$ & $0.1 \mathrm{pptv}$ & $2.3 \mathrm{pptv}$ & 0.9 pptv \\
\hline
\end{tabular}

The corresponding diameter ranges are: (i) $0.4-0.56 \mathrm{~nm}$, (ii) $0.56-0.75 \mathrm{~nm}$, (iii) $0.75-1.00 \mathrm{~nm}$, (iv) $1.00-1.33 \mathrm{~nm}$, (v) $1.33-1.75 \mathrm{~nm}$ and (vi) $1.75-2.37 \mathrm{~nm}$ (Fig. 11). In order to understand the plots there are key features to be taken into account. If any stable air ion (cluster) consists of a multitude of different compounds, e.g. sulphuric acid, organics and water with different charge affinities, the charged fraction is dependent only on the coagulation sink of the clusters to ambient particles, but not on individual compound lifetimes. The coagulation sink however stays rather constant from spring to autumn and disagrees with the clear seasonal cycle of the ratio observed for the investigated second size section. Thus, if there is a notable contribution from sulphuric acid derived clusters, it can be considered as one of the sensitivity cases shown in Fig. 10.

Additionally, Fig. 11 shows a clear seasonal pattern for the lowest four size sections shown, i.e. below about $1.5 \mathrm{~nm}$ in diameter, but not above. At larger sizes only a scattering of the ratio is apparent, indicating a change from molecular or tiny cluster type (only a couple of molecules) to a reasonably well mixture of the cluster composition. It is also apparent that there is a shift from excess negative charges at small sizes to excess positive charges at larger sizes, indicating a clear change in composition. Therefore we conclude that at least below the third size section there are charged single molecules detected as air ions.

Finally, if we have to assume single molecules or clusters with either a sufficiently short ambient lifetime, i.e. radicals, or with a preference for negative charging, we can test the concentration measured with gas-phase concentrations of measured and derived inorganic compounds such as $\mathrm{SO}_{2}, \mathrm{SO}_{3}, \mathrm{HSO}_{3}$ and sulphuric acid. None of the sulphur

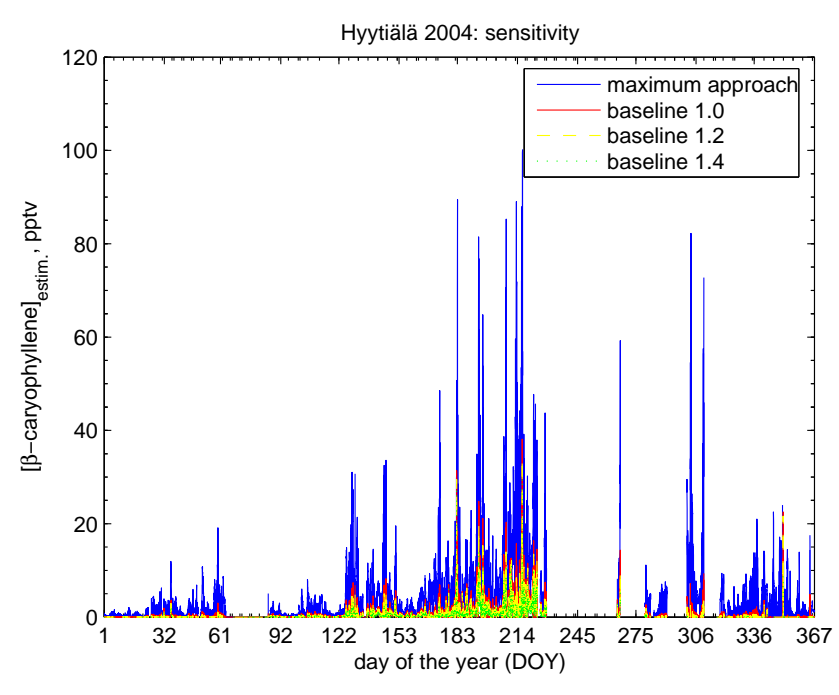

Fig. 10. Intercomparison of four different assumptions in order to derive the ambient sesquiterpene concentration during 2004. The major difference is shift in the onset of ambient concentrations and in the maximum during summer.

and nitrogen compounds indicated a relationship with the air ion concentration of the second size section in a scatter plot. Only the already mentioned relationship with water vapour and ozone is significant. Thus, we assume other compounds to contribute to the investigated air ions to only a minor extend at maximum. 

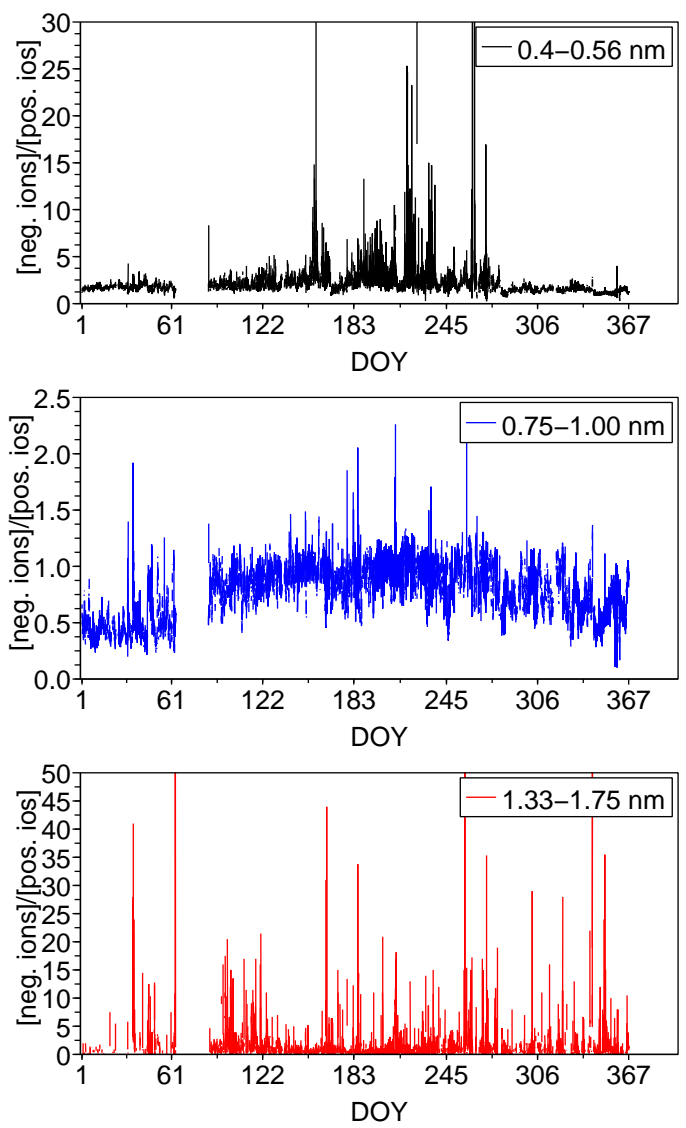
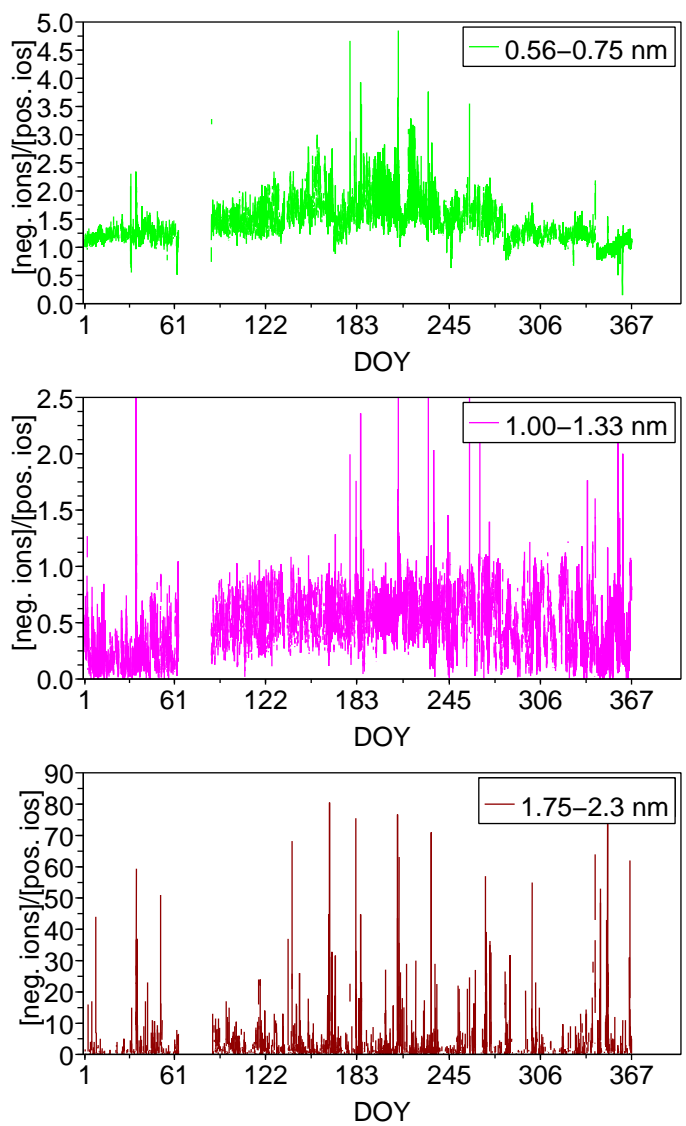

Fig. 11. Ratio of negative to positive air ions measured by the BSMA instrument for the lowest six size bins in 2004: (i) $0.4-0.56 \mathrm{~nm}$, (ii) $0.56-0.75 \mathrm{~nm}$, (iii) $0.75-1.00 \mathrm{~nm}$, (iv) $1.00-1.33 \mathrm{~nm}$, (v) $1.33-1.75 \mathrm{~nm}$ and (vi) $1.75-2.37 \mathrm{~nm}$ in mobility derived diameter.

\subsection{Comparison of estimated concentrations to ambient emission measurements}

The assumption of all air ions to consist of sCIs (maximum approach, see before) was checked the following way: In order to obtain a reasonable sesquiterpene mixing ratio at the inlet of the air ion spectrometer $(\approx 2 \mathrm{~m}$ in height), we use the emission measurements at shoot level (height $=13 \mathrm{~m}$ ) and assume a logarithmic vertical wind profile at noon below the canopy and constant vertical velocity within. The maximum emission rate measured by Hakola et al. (2006) was $198.2 \mathrm{ng} g(\mathrm{dw})^{-1} \mathrm{~h}^{-1}$ at noon of 3 August 2004 at shoot level. During the time needed to transport the emitted sesquiterpene molecules from the shoot level towards the instruments inlet at $2 \mathrm{~m}$, a fraction of the sesquiterpene molecules is destroyed by ambient ozone molecules. The concentration of ozone was $42 \mathrm{ppbv}$ at that time. The time available for reacting is given by the local vertical wind profile inside the canopy and below. Assuming a mean velocity $\overline{\mathrm{w}}$ of $0.7 \frac{\mathrm{m}}{\mathrm{s}}\left(0.9 \frac{\mathrm{m}}{\mathrm{s}}\right.$ within the canopy $(7-13 \mathrm{~m}$ in height $)$ and on average $0.45 \frac{\mathrm{m}}{\mathrm{s}}$ below (between 2 and $7 \mathrm{~m}$ )) this results in a $\Delta \mathrm{t}$ of $15.7 \mathrm{~s}$ and yields a reduced fraction of sesquiterpenes emitted of 0.83 at $2 \mathrm{~m}$ in height. Additionally, the emitted terpene is distributed on its way downward within $11 \mathrm{~m}$, which gives $\frac{1}{11}=0.091$. Next, we use this at the inlet of the BSMA: The emission flux ( $\left.F_{\text {sesqui }}\right)$ from above is in balance with the major sink, i.e. the reaction with ozone.

$$
\begin{aligned}
E_{\text {sesqui }} & =\frac{192.8 \frac{g}{g(d w) \cdot h} \cdot 10^{-9} \frac{g}{n g} \cdot N_{A}}{3600 \frac{\mathrm{s}}{h} \cdot M_{\text {sesqui }}} \\
F_{\text {sesqui }} & =E_{\text {sesqui }} \cdot 0.83 \cdot \text { biomass } \cdot 0.091 \\
& =k_{\text {sesqui }}^{O_{3}}\left[O_{3}\right][\text { sesqui }] \\
{[\text { sesqui }] } & =\frac{F_{\text {sesqui }} \cdot 10^{-6} \frac{\mathrm{cm}^{3}}{\mathrm{~m}^{3}} \cdot 0.83 \cdot \text { biomass } \cdot 0.091}{k_{\text {sesqui }}^{O_{3}}\left[O_{3}\right]}
\end{aligned}
$$

$N_{A}$ abbreviates the Avogadro number of $6.022 \times 10^{23} \frac{\text { molecules }}{\mathrm{mol}}$ and $M_{\text {sesqui }}$ the molar mass of sesquiterpenes $\left(204 \frac{\mathrm{g}}{\mathrm{mol}}\right)$. The biomass at Hyytiälä is approximately $300 \frac{\mathrm{g}}{\mathrm{m}^{2}}$. By doing so we calculated maximum sesquiterpene mixing ratio at noon on 3 August of $12.3 \mathrm{pptv}$, which corresponds nicely to the 12.6 pptv obtained by our maximum approach given above. Therefore, we are confident in the present results and the tool developed. 
6.4 "Event days in December 2004"

During analysis of the data two "exceptional" days in December 2004 became apparent. Most predominant is the 15 th. No change in $\mathrm{SO}_{2}$ or water vapour concentration could be observed, but in the ozone concentration. The latter declined to extremely low values close to a few ppbv. Simultaneously, the air ion concentration between 0.56 and $0.75 \mathrm{~nm}$ increased to $1000 \mathrm{~cm}^{-3}$, not observed throughout the entire year elsewhere (average $=300 \mathrm{~cm}^{-3}$ ). Once the ozone concentration increased, the air ions declined. This is demonstrated in Fig. 12. The cause for ozone to decline is found clearly by an increase of $\mathrm{NO}_{\mathrm{x}}$ concentrations measured as well. But if there was a high amount of a reactive VOC it might contribute somewhat in this case too. Temperature was measured below the frost point. During this episode the wind was coming from the station buildings and it was evening. The latter caused a stable boundary layer preventing mixing with air from above. Probably a sauna was prepared by burning fresh wood, which contained stored VOCs like monoand sesquiterpenes beneath the bark. A similar but less pronounced "event" was observed during the 29th and much less on the 22th because of different wind pattern. This observation might have been linked to regular sauna times at the station. Unfortunately, there is no information about the schedules and the usage of different materials (woods, electrical heating) available anymore. But there is no other process likely for this. Aromatic VOCs e.g. are much less reactive with ozone and wouldn't have caused such a large effect, nor any other reaction plausible at that time. Nor is the $\mathrm{SO}_{2}$ concentration changing as well as no significant $\mathrm{OH}$ production calculated at that time, which is needed for sulphuric acid production. Similarly, $\mathrm{NO}_{\mathrm{x}}$ is not in the expected ion mass range and nitric acid clusters would not have had sufficient $\mathrm{OH}$ to form (darkness). However there is a possible contribution of any $\mathrm{NO}_{\mathrm{x}}$ derivative to the air ions measured and thus, the data was excluded from the seasonal estimate.

\subsection{Daily pattern of ambient sesquiterpene concentrations}

But how does the daily pattern of the ambient sesquiterpene concentration look like during different seasons when applying this approach? In order to briefly investigate this we have selected one day per season. The individual pattern can be seen in Fig. 13.

When taking a look on this figure there are some issues of interest: First, the volume mixing ratio is rather different during the different season as expected. Second, the maximum concentration is achieved in the afternoon during winter and spring, which makes sense since the temperature and stress effects are most intense on the vegetation. Third, and this is the most interesting aspect, this is not found for summer and autumn. During this time the mixing ratio and thus concentration is highest throughout the year and peaks in the morning but declines during the afternoon. Why that? There

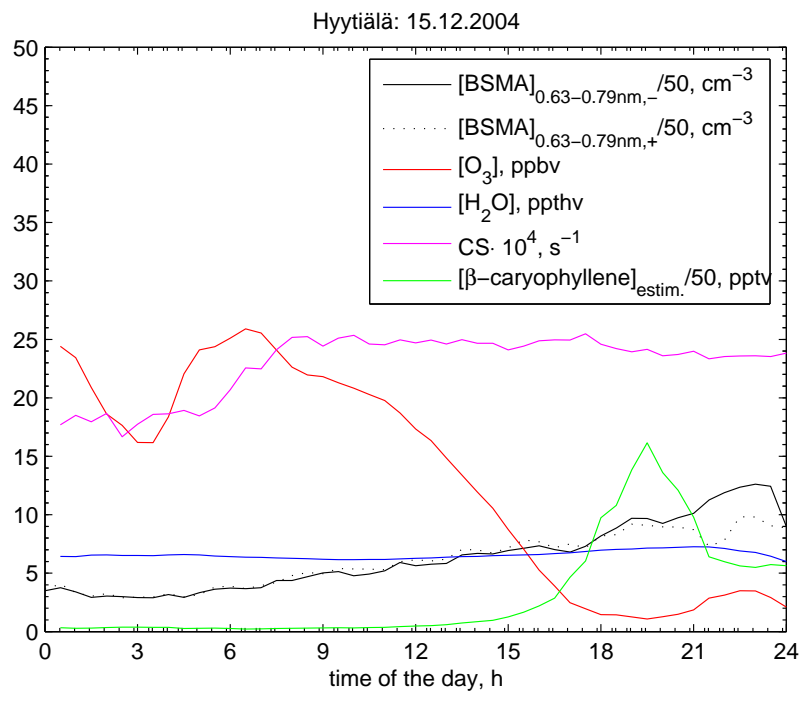

Fig. 12. "Event" day of extremely high air ion concentration between 0.56 and $0.75 \mathrm{~nm}$ : 15 December 2004. Significant correlation is only found with declining ozone.

seems to be a pool or storage of sesquiterpenes present within the needles that is emptied during the morning due to the high emission rates. The formation or otherwise the transport (not really water-soluble) via the water cycle in the tree is fairly small and represents the limit of the emission here. Once the emission declines during the evening the pool is getting refilled and the emission potential increases again during the cooler temperature.

6.6 Intercomparison to ambient emission measurements of sesquiterpenes

When calculating chemical compound concentrations in ambient air from indirect measurements any intercomparison to direct measurements is needed. However, no direct ambient concentration measurements are available for the site of interest, but spotlike emission measurements as were used in the Sect. 6.1. These emission measurements have been included in Fig. 9 (right) (Tarvainen et al., 2005; Hakola et al., 2006). They indicate, as expected, a maximum of emissions during summer, when the stress on the forest ecosystem is most intense, rising already during the end of March or beginning of April. By intercomparing the results of Tarvainen et al. (2005) and Hakola et al. (2006) with the obtained sesquiterpene annual profile both have the same pattern and seasonal trend. Nevertheless, boundary layer micrometeorology needs to be taken into account to move the emitted molecules to the inlet of the air ion instruments. A strong mixing should favour the increase in air ions of the size section between 0.56 and $0.75 \mathrm{~nm}$ in diameter, which seems to be apparent during spring. Additionally, the good correlation of sesquiterpene emissions with the emission of 

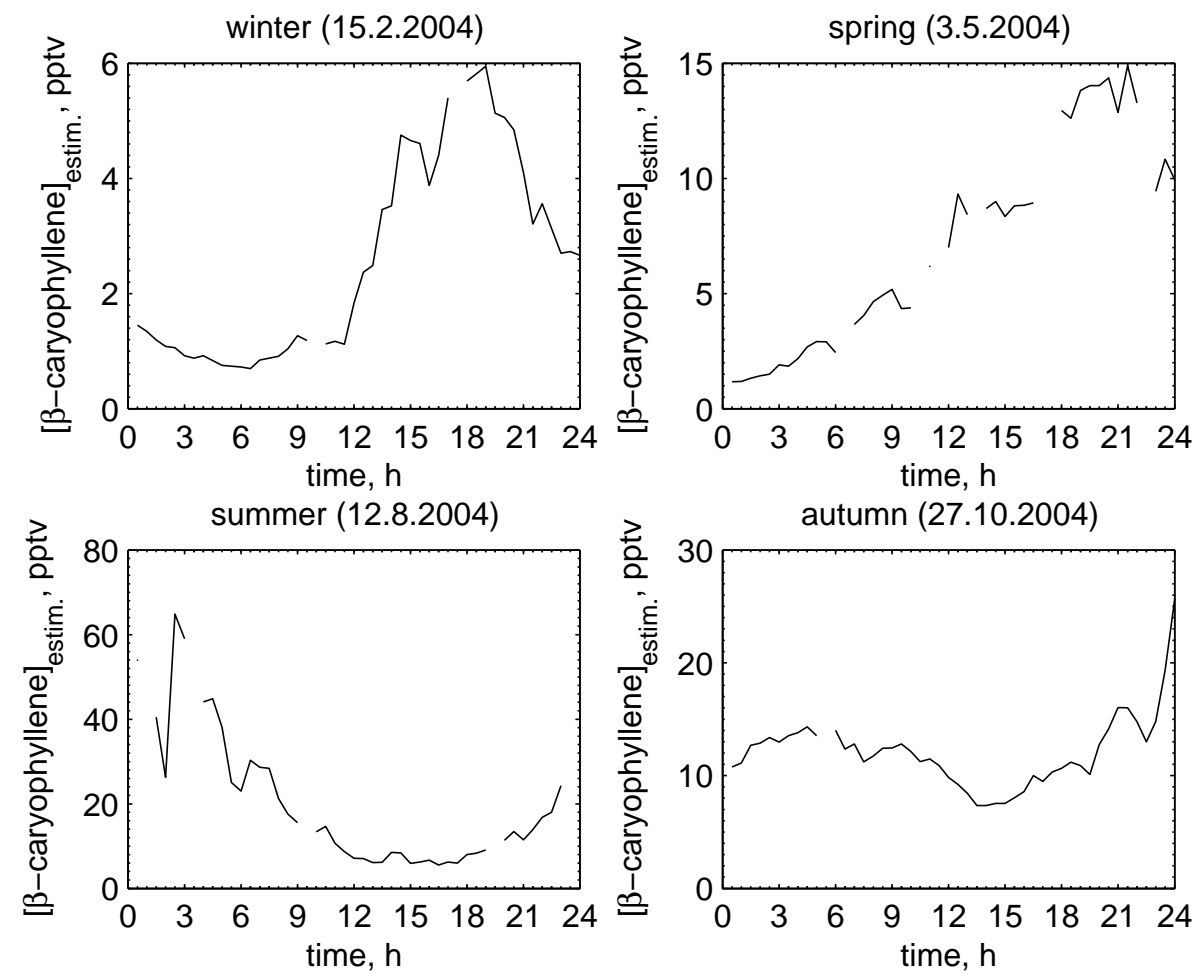

Fig. 13. Displayed is the daily behaviour of the calculated sesquiterpene concentration at the air ion instruments inlet (BSMA) on four exemplary days in spring, summer, autumn and winter of 2004.

water-soluble monoterpenoids (linalool and cineol) but not with monoterpenes during that time is a key information: The higher the water flux of the trees (forest) towards the gas-phase, the higher are the sesquiterpene emissions. This is apparent in Eq. (43), when air ion concentrations do not decrease as much as during summer in the section of the air ion maximum concentration. In this context, the obvious difference between the individual years is most likely related to ambient meteorological conditions. 2003 was a significantly warmer year than 2004, in which the summer was affected by enhanced rainfall. The more humid conditions and the lower temperature caused less stress for the vegetation and slower respiration, reducing the water vapour and VOC fluxes from the biosphere to the atmosphere.

Nevertheless, all the presented results remain indications for the molecular composition of air ions only, but need to be proven once these compounds can be detected by instruments in the ambient gas-phase reasonably well too. Thus, the presented hypothesis with respect to stabilised Criegee intermediates and the related maximum sesquiterpene concentration estimation require a detailed intercomparison with field data of sesquiterpene measurements where possible and future studies to confirm this.

\section{Conclusions}

In this study we have investigated the origin of the air ion maximum at mobility diameters of $0.56-0.75 \mathrm{~nm}$. By using further information such as the ratio of negative and positive air ions in that section, about its seasonality and about trace gas concentrations, we linked this to an intermediate formed in the reaction of biogenic sesquiterpenes and ozone. Electron and proton affinities, calculated for these intermediates, are reasonably high and support this link. Further possible candidates such as sulphuric acid clusters or other organic compounds were not capable in explaining the observed behaviour of the air ions, since their charging state depends mainly on the condensation sink which causes a too long ambient lifetime to explain the nearly twice as large negative to positive air ion concentration ratio during summer. Moreover, the seasonality of this ratio is not captured by other candidates with ambient lifetimes longer than a few seconds. The stabilised Criegee intermediate however with an ambient lifetime between about 0.5 (summer) and $1.5 \mathrm{~s}$ (winter), which is destroyed by the present water vapour agrees fairly well. By assuming the air ions to be these intermediates we can calculate the ambient sesquiterpene concentrations with a high time resolution and for a very long time period ( 2 years) for the first time. These estimated concentrations agree nicely with the pattern of spotwise done emission 
measurements at trees closed by. The estimated ambient concentrations vary quite strong: fairly high concentrations of sesquiterpenes are obtained especially during summer time (>100 pptv) and tiny concentrations of less than a pptv or even a tenth of it during winter. The presence of these VOCs will certainly affect the canopies ozone concentration and protect the plants from harmful stress.

However, it should be noted that the results are only representative for the situation in the boreal forest studied, since the air ion measurement is only a physical but not a chemical detection method. They might certainly be valid in other environments. Nevertheless, for the identification of the air ions further information such as of trace gases is essential to know. Therefore, air ions at different sites such as at urban or remote sites or in the free troposphere will most probably consist of different species. Note as well that we considered the major source of the air ions in the size section studied to be formed by the same reaction throughout the year, which remains an issue to be studied in the future, but this seems to be reasonable for the conditions found at Hyytiälä.

Since the information about ambient sesquiterpenes and their emission behaviour is currently scarce and the global emission in global models is assumed to be identical to monoterpenes, a notable gap of knowledge needs to be investigated and explained. Hakola et al. (2006) showed that this link between mono- and sesquiterpenes is not valid for boreal forest environments. By taking into account the area of interest, this issue might be a key to understand the large ozone sink detected in the forests and boundary layer chemistry. Moreover, the results will definitely impact on local aerosol formation and growth. Nevertheless, this remains a further topic to be investigated. Therefore it is essential to know about the chemical properties of the neutrals and the air ions gained. This complicates the usual approach of steadystate charging assumption when doing measurements and a change in the chemical composition of neutrals will affect the charging ratio or overcharging significantly.

\section{Appendix A}

\section{Quantum chemistry glossary}

Quantum chemistry is the numerical solving of the electronic Schrödinger equation for a system of atoms and molecules in order to calculate properties of chemical interest. For systems containing multiple atoms, a variety of approximations must be made for the calculations to be computationally feasible. These usually include the following:

- Atomic nuclei are assumed to move according to classical mechanics.

- Relativistic effects are normally ignored.

- The electronic wave function is expressed as a antisymmetrized product of one-electron wave functions, which in turn are expressed as linear combinations of basis functions obtained from some basis set.

- Electron correlation is treated approximately (or sometimes not at all), either by the use of an exchangecorrelation electron density functional, or by the use of excitation operators.

- If considered, thermal corrections to enthalpies and free energies are normally calculated using rigid rotor and harmonic oscillator approximations.

For further details see e.g. Jensen (2007) or Foresman and Frisch (1996) and references therein.

For standard quantum chemistry calculations, the typical notation is: method/basis set, where the "method" is the set of approximations and techniques used to calculate e.g. electronic energies and gradients (or in some cases other properties such as electron affinities) from the Schrödinger equation.

\section{A1 Methods}

In this study two methods have been used:

- UB3LYP, the spin-unrestricted form of the B3LYP density functional, which is composed of Becke's 3 parameter electron exchange functional and the LeeYoung-Parr electron correlation functional. The term "spin - unrestricted" implies that the spatial orbitals of alpha and beta-spin electrons are not constrained to be identical. The B3LYP functional has been hugely successful in predicting chemical properties of a large variety of compounds. However, like almost all density functional methods, it performs poorly for e.g. weakly bound systems. Chemical properties calculated for radical and biradical species - such as Criegee Intermediate investigated in this study - should also be considered to be of a qualitative nature only.

- OVGF(Frozen-Core), the Outer Valence Green's Function electron propagator method for calculation of correlated electron affinities and ionization potentials. Unlike B3LYP, OVGF is not a general-purpose method: it does not calculate e.g. total electronic energies or optimize molecular geometries, but only computes electron affinities and ionization potentials. These are obtained as the poles of electron propagator operators corresponding to the addition or removal of electrons. The term "Frozen-Core" implies that the correlation of core electrons is ignored. This is expected to have only a small effect on the chemical properties as they are largely determined by the interactions of valence electrons only. In principle the OVGF method should yield more accurate results than e.g. density functional methods, but there is very little data on the performance of the OVGF method for biradical species such as the Criegee Intermediate. 
In studies of gas-phase molecules, the basis functions are usually linear combinations of atom-centered Gaussian functions of the type $N Y_{m, l}(\theta, \phi) r^{2 n-2-l} e^{-\xi r 2}$, where $Y_{m, l}$ is a spherical harmonic, $N$ and $\xi$ are constants, and $n, l$ and $m$ are the quantum numbers of atomic physics. E.g. $l=0$ corresponds to s-type orbitals, $l=1$ to $\mathrm{p}$-type orbitals, $l=2$ to d-type orbitals and so on.

Depending on the so-called degree of contraction, one basis function consists of between one and ten Gaussian functions with the same quantum numbers but different values of $N$ and $\xi$. Basis sets are classified according to the number of basis functions per electron: double- $\xi$ sets contain two, triple- $\xi$ sets three and so on. Normally only the valence electrons are given. Multiple basis functions, and the basis sets are correspondingly denoted valence double- $\xi$, valence triple- $\xi$, etc. In order to properly describe chemical bonding, additional so-called polarization functions usually need to be added, corresponding to higher values of the quantum number $l$. For the description of intermolecular interactions, or for the accurate comparison of different charging states, diffuse functions, which correspond to small values of the constant $\xi$, are also needed.

The size of the basis set needed in order to accurately compute some property is highly dependent on the method used and the system in question. E.g. for density functional methods, a valence double- $\xi$ basis with one set of polarization functions generally yields qualitatively reliable molecular geometries and energies, while valence triple- $\xi$ basis sets with multiple polarization functions may be required for quantitative accuracy.

It should be remembered that if the chosen method does not describe the system well, even the largest basis sets will lead to incorrect results.

\section{A2 Basis sets}

In this study, three different basis sets have been used:

i.) $6-31+G(d, p)$, a valence - double- $\xi$ basis set with one $d-$ type polarization function for each non-hydrogen atom, one p-type polarization function for each hydrogen atom, and one diffuse function for each non-hydrogen atom.

ii.) aug-cc-pV(D+d)Z, a valence - double- $\xi$ basis set with two polarization function for each hydrogen atoms and first-row element ( $p$ - and d-type, respectively) and three (d-type) polarization functions for the second-row elements. One of the polarization functions in each case is also diffuse, and there are additionally more two diffuse functions for each non-hydrogen atom and one diffuse function for each hydrogen atom.

iii.) $6-311++\mathrm{G}(\mathrm{d}, \mathrm{p})$, a valence - triple- $\xi$ basis set with one d-type polarization function for each non-hydrogen atom, one p-type polarization function for each hydrogen atom, and one diffuse function for each atom.
Acknowledgements. The authors would like to thank their colleagues at the universities of Helsinki and Tartu for support and discussion as well as all the involved people in the measurements at the field forest site in Hyytiälä. The BACCI project is gratefully acknowledged for financial support.

Edited by: K. Hämeri

\section{References}

Atkins, P. and de Paula, J.: Atkins' physical chemistry, 7th edit., Oxford Univ. Press., Oxford, 2002.

Atkinson, R., Baulch, D. L., Cox, R. A., Crowley, J. N., Hampson, R. F., Hynes, R. G., Jenkin, M. E., Rossi, M. J., and Troe, J.: Evaluated kinetic and photochemical data for atmospheric chemistry: Volume II - reactions of organic species, Atmos. Chem. Phys., 6, 3625-4055, 2006,

http://www.atmos-chem-phys.net/6/3625/2006/.

Becke, A. D.: Density-functional thermochemistry. III. The role of exact exchange, J. Chem. Phys., 98, 5648-5652, 1993.

Boy, M., Kulmala, M., Ruuskanen, T. M., Pihlahtie, M., Reissell, A., Aalto, P. P., Keronen, P., Dal Maso, M., Hellen, H., Hakola, H., Jansson, R., Hanke, M., and Arnold, F.: Sulphuric acid closure and contribution to nucleation mode particle growth, Atmos. Chem. Phys., 5, 863-878, 2005, http://www.atmos-chem-phys.net/5/863/2005/.

Bäck, J., Hari, P., Hakola, H., Juurola, E., and Kulmala, M.: Dynbamics of monoterpene emissions in Pinus sylvestris during early spring, Boreal Environ. Res., 10, 409-424, 2005.

CRC Handbook: CRC Handbook of chemistry and physics, edited by: Linde, D. R., CRC press, Boca Raton, 1998.

Criegee, R.: Mechanismus der Ozonolyse. Angew. Chem., 87, 765771, 1975.

Dal Maso, M., Kulmala, M., Riipinen, I., Wagner, R., Hussein, T., Aalto, P. P., and Lehtinen, K. E. J.: Formation and growth of fresh atmospheric aerosols: eight years of aerosol size distribution data from SMEAR II, Hyytiälä, Finland, Boreal Environ. Res., 10, 323-336, 2005.

Davidson, J. A., Fehsenfeld, F. C., and Howard, J. C.: The heats of formation of $\mathrm{NO}_{3}^{-}$and $\mathrm{NO}_{3}^{-}$association complexes with $\mathrm{HNO}_{3}$ and HBr, Int. J. Chem. Kinet., 9, 17-29, 1977.

Eisele, F. L. and Tanner, D. J.: Identification of ons in continental air. J. Geophys. Res., 95(D12), 20 539-20 550, 1990.

Eisele, F. L., Lovejoy, E. R., Kosciuch, E., Moore, K. F., Mauldin III, R. L., Smith, J. N., McMurry, P. H., and Iida, K.: Negative atmospheric ions and their potential role in ion-induced nucleation, J. Geophys. Res., 111, D04305, doi:10.1029/2005JD006568, 2006.

Ferguson, E. E. and Arnold, F.: Ion chemistry of the stratosphere, Accounts Chem. Res., 14, 327-334, 1981.

Foresman, J. B. and Frisch, Æ.: Exploring Chemistry with Electronic Structure Methods, 2nd edition, Gaussian, Inc., Wallingford CT, U.S., 1996.

Friedlander, S. K.: Smoke, dust and haze, 2nd edit., Oxford Univ. Press., Oxford, 2000.

Frisch, M. J., Trucks, G. W., Schlegel, H. B., Scuseria, G. E., Robb, M. A., Cheeseman, J. R., Montgomery, Jr., J. A., Vreven, T., Kudin, K. N., Burant, J. C., Millam, J. M., Iyengar, S. S., Tomasi, J., Barone, V., Mennucci, B., Cossi, M., Scalmani, G., Rega, N., 
Petersson, G. A., Nakatsuji, H., Hada, M., Ehara, M., Toyota, K., Fukuda, R., Hasegawa, J., Ishida, M., Nakajima, T., Honda, Y., Kitao, O., Nakai, H., Klene, M., Li, X., Knox, J. E., Hratchian, H. P., Cross, J. B., Bakken, V., Adamo, C., Jaramillo, J., Gomperts, R., Stratmann, R. E., Yazyev, O., Austin, A. J., Cammi, R., Pomelli, C., Ochterski, J. W., Ayala, P. Y., Morokuma, K., Voth, G. A., Salvador, P., Dannenberg, J. J., Zakrzewski, V. G., Dapprich, S., Daniels, A. D., Strain, M. C., Farkas, O., Malick, D. K., Rabuck, A. D., Raghavachari, K., Foresman, J. B., Ortiz, J. V., Cui, Q., Baboul, A. G., Clifford, S., Cioslowski, J., Stefanov, B. B., Liu, G., Liashenko, A., Piskorz, P., Komaromi, I., Martin, R. L., Fox, D. J., Keith, T., Al-Laham, M. A., Peng, C. Y., Nanayakkara, A., Challacombe, M., Gill, P. M. W., Johnson, B., Chen, W., Wong, M. W., Gonzalez, C., and Pople, J. A.: Gaussian 03, Revision C.02, Gaussian, Inc., Wallingford CT, 2004.

Fuchs, N. A. and Sutugin, A. G.: High dispersed aerosols: in: Topics in current aerosol research, edited by: Hidy, G. M. and Brock, J. R., vol. 2, Pergamon Press, Oxford, 1971.

Goldstein, A. H., McKay, M., Kurpius, M. R., Schade, G. W., Lee, A., Holzinger, R., and Rasmussen, R.: Forest thinning experiment confirms ozone deposition to forest canopy is dominated by reaction with biogenic VOCs, Geophys. Res. Lett., 31, L22106, doi:10.1029/2004GL021259, 2004.

Geiger, H., Barnes, I., Becker, K.-H., Bohn. B., Brauers, T., Donner, B., Dorn, H.-P., Elend, M., Freitas Dinis, C. M., Grossmann, D., Hass, H., Hein, H., Hoffmann, A., Hoppe, L., Hülsemann, F., Kley, D., Klotz, B., Libuda, H. G., Maurer, T., Mihelcic, D., Moortgat, G. K., Olariu, R., Neeb, P., Poppe, D., Ruppert, L., Sauer., C. G., Shestakov, O., Somnitz, H., Stockwell, W. R., Thüner, L. P., Wahner, A., Wiesen, P., Zabel, F., Zellner, R., and Zetzsch, C.: Chemical mechanism development, J. Atmos. Chem., 42, 323-357, 2002.

Großmann, D.: Die Gasphasenozonolyse von Alkenen in Gegenwart von Wasserdampf als Quelle für Wasserstoffperoxid und organische Peroxide in der Atmosphäre, Ph.D. thesis, University Mainz, Mainz, 1999.

Guenther, A., Hewitt, C. N., Erickson, D., Fall. R., Geron, C., Graedel, T., Harley, P., Klinger, L., Lerdau, M., McKay, W. A., Pierce, T., Scholes, B., Steinbrecher, R., Tallamraju, R., Taylor, J., and Zimmerman P.: A global model of natural volatile organic compound emissions, J. Geophys. Res., 100(D5), 8873$8892,1995$.

Hakola, H., Tarvainen, V., Laurila, T., Hiltunen, V., Hellén, H., and Keronen, P.: Seasonal variation of VOC concentrations above a boreal coniferous forest, Atmos. Environ., 37, 1623-1637, 2003.

Hari, P. and Kulmala, M.: Station for measuring ecosystematmosphere relations, Boreal Environ. Res., 10, 315-322, 2005.

Hakola, H., Tarvainen, V., Bäck, J., Ranta, H., Bonn, B., Rinne, J., and Kulmala, M.: Seasonal variation of mono- and sesquiterpene emission rates of Scots pine, Biogeosciences, 2, 93-101, 2006, http://www.biogeosciences.net/2/93/2006/.

Hellén, H., Hakola, H., Reissell, A., and Ruuskanen, T. M.: Carbonyl compounds in boreal coniferous forest air in Hyytiälä, Southern Finland, Atmos. Chem. Phys., 4, 1771-1780, 2004, http://www.atmos-chem-phys.net/4/1771/2004/.

Hirsikko, A., Laakso, L., Hõrrak, U., Aalto, P. P., Kerminen, V.M., and Kulmala, M.: Annual and size dependent variation of growth rates and ion concentrations in boreal forest, Boreal Environ. Res., 10, 357-369, 2005.
Hoppel, W. A. and Frick, G. M.: Ion-aerosol attachment coefficients and the steady-state charge distribution on aerosols in a bipolar ion environment, Aerosol Sci. Technol., 5, 1-21, 1986.

Israël, H.: Atmospheric electricity, vol. I, Israel program for Sci. Transl. \& NSF, Jerusalem, 1970.

Jensen, F.: Introduction to Computational Chemistry, 2nd edition, John Wiley \& Sons, Ltd, West Sussex, UK, 2007.

Kauppila, T. J., Kuuranne, T., Meurer, E. C., Eberlin, M. N., Kotiaho, T., and Kostiainen, R.: Atmospheric pressure photoionization mass spectrometry. Ionization mechanism and the effect of solvent on the ionization of naphtalenes, Anal. Chem., 74, 5470 5479, 2002.

Kilpatrick, W. D.: An experimental mass-mobility relation for ions in the air at atmospheric pressure, Proc. Annu. Conf. Massspectrosc., 19, 320-325, 1971.

Kulmala, M., Pirjola, L., and Mäkelä, J. M.: Stable sulphate clusters as a source of new atmospheric particles, Nature, 404, 66-69, 2000.

Kulmala, M., Hämeri, K., Aalto, P. P., Mäkelä, J. M., Pirjola, L., Douglas Nilsson, E., Buzorius, G., Rannik, Ü., Dal Maso, M., Seidl, W., Hoffmann, T., Janson, R., Hansson, H.-C., Viisanen, Y., Laaksonen, A., and O'Dowd, C. D.: Overview of the international project on biogenic aerosol formation in the boreal forest (BIOFOR), Tellus, 53B, 324-343, 2001.

Laakso, L., Mäkelä, J. M., Pirjola, L., and Kulmala, M.: Model studies on ion-induced nucleation in the atmosphere, J. Geophys. Res., 107(D20), 4427, doi:10.1029/2002JD002140, 2002.

Lee, C., Yang, W., and Parr, R. G.: Development of the ColleSalvetti correlation-energy formula into a functional of the electron density, Phys. Rev. B, 37, 785-789, 1988.

Loreto, F., Mannozzi, M., Maris, C., Nascetti, P., Ferranti, F., and Pasqualini, S.: Ozone quenching properties of isoprene and its antioxidant role in leaves, Plant Physiol., 126, 993-1000, 2001.

Perkins, M. D. and Eisele, F. L.: First mass spectrometric measurements of atmospheric ions at ground level, J. Geophys. Res., 89(D6), 9649-9657, 1984.

Pirjola, L., Kulmala, M., Wilck, M., Bischoff, A., Stratmann, F., and Otto, E.: Formation of sulphuric acid aerosols and cloud condensation nuclei: An expression for significant nucleation and model comparison, J. Aerosol Sci., 30, 1079-1094, 1999.

Seinfeld, J. H. and Pandis, S. N.: Atmospheric chemistry and physics, Wiley Interscience Pub., New York, 1998.

Shu, Y. and Atkinson, R.: Rate constants for the gas-phase reactions of $\mathrm{O}_{3}$ with a series of terpenes and $\mathrm{OH}$ radical formation from the $\mathrm{O}_{3}$ reactions with sesquiterpenes at $296 \pm 2 \mathrm{~K}$, Int. J. Chem. Kin., 26, 1193-1205, 1994.

Shu, Y. and Atkinson, R.: Atmospheric lifetimes and fates of a series of sesquiterpenes, J. Geophys. Res., 100(D4), 7275-7281, 1995.

Tammet, H.: Size and mobility of nanometer particles, clusters and ions, J. Aerosol Sci., 26, 459-475, 1995.

Tammet, H.: Reduction of air ion mobility to standard conditions, J. Geophys. Res., 103(D12), 13 933-13 937, 1998.

Tammet, H.: Balanced Scanning Mobility Analyzer, in: Proc. 16th International Conference on Nucleation \& Atmospheric Aerosols, Kyoto, 2004.

Tammet, H.: Simulation tool for atmospheric aerosol nucleation bursts, J. Aerosol Sci., 36, 173-196, 2005.

Tammet, H.: Continuous scanning of the mobility and size distribu- 
tion of charged clusters and nanometer particles in atmospheric air and the Balanced Scanning Mobility Analyzer BSMA, Atmos. Res., 82, 523-535, 2006.

Tammet, H., Hõrrak, U., Laakso, L., and Kulmala, M.: Factors of air ion balance in a coniferous forest according to measurements in Hyytiälä, Finland, Atmos. Chem. Phys., 6, 3377-3390, 2006, http://www.atmos-chem-phys.net/6/3377/2006/.

Tarvainen, V., Hakola, H., Hellén, H., Bäck, J., Hari, P., and Kulmala, M.: Temperature and light dependence of the VOC emissions of Scots pine, Atmos. Chem. Phys., 5, 989-998, 2005, http://www.atmos-chem-phys.net/5/989/2005/.

Vana, M., Kulmala, M., Dal Maso, M., Hõrrak, U., and Tamm, E.: Comparative study of nucleation mode aerosol particles and intermediate air ions formation events at three site, J. Geophys. Res., 109, D17201, doi:10.1029/2003JD004413, 2004.

Viggiano, A. A., Perry, R. A., Albritton, D. L.,Ferguson, E. E., and Fehsenfeld, F. C.: The role of $\mathrm{H}_{2} \mathrm{SO}_{4}$ in stratospheric negativeion chemistry, J. Geophys. Res., 85(NC8), 4551-4555, 1980. von Niessen, W., Schirmer, J., and Cederbaum, L. S.: Computational methods for the one-particle Green's function, Comput. Phys. Rep., 1, 57-125, 1984.

Vuorinen, T., Nerg, A.-M., Vapaavuori, E., and Holopainen, J. K.: Emission of volatile organic compounds from two silver birch (Betula pendula Roth) clones grown under ambient and elevated $\mathrm{CO}_{2}$ and different $\mathrm{O}_{3}$ concentrations, Atmos. Environ., 39, 1185-1197, 2005.

Went, F. W.: Blue hazes in the atmosphere, Nature, 187, 641-643, 1960.

Zakrzewski, V. G. and Ortiz, J. V.: Semidirect algorithms for thirdorder electron propagator calculations, Int. J. Quantum Chem., 53, 583-590, 1995. 